\title{
Amplified Cold Transduction in Native Nociceptors by M-Channel Inhibition
}

\author{
Irina Vetter, ${ }^{1,2 *}$ Alexander Hein, ${ }^{2,6 *}$ Simon Sattler, ${ }^{2,3 *}$ Sabine Hessler, ${ }^{2 *}$ Filip Touska, ${ }^{2,3}$ Elisangela Bressan, ${ }^{2}$ \\ Andres Parra, ${ }^{4}$ Ulrich Hager, ${ }^{2}$ Andreas Leffler, ${ }^{5}$ Stepana Boukalova, ${ }^{3}$ Matthias Nissen, ${ }^{2}$ Richard J. Lewis, ${ }^{1}$ \\ Carlos Belmonte, ${ }^{4}$ Christian Alzheimer, ${ }^{2}$ Tobias Huth, ${ }^{2}$ Viktorie Vlachova, ${ }^{3}$ Peter W. Reeh, ${ }^{2}$ \\ and Katharina Zimmermann ${ }^{2}$ \\ ${ }^{1}$ Institute for Molecular Bioscience, The University of Queensland, St. Lucia 4072, Queensland, Australia, ${ }^{2}$ Department of Physiology and Pathophysiology, \\ Friedrich-Alexander-Universität Erlangen-Nürnberg, 91054 Erlangen, Germany, ${ }^{3}$ Department of Cellular Neurophysiology, Institute of Physiology, Academy of \\ Sciences of the Czech Republic, CZ-14220 Prague, Czech Republic, ${ }^{4}$ Instituto de Neurociencias de Alicante, Universidad Miguel Hernandez-Consejo Superior de \\ Investigaciones Cientificas, 03550 San Juan de Alicante, Spain, ${ }^{5}$ Department of Anesthesiology and Intensive Care, Medical School Hannover, 30625 Hannover, \\ Germany, and ${ }^{\circ}$ Department of Gynecology and Obstetrics, Friedrich-Alexander-Universität Erlangen-Nürnberg, 91054 Erlangen, Germany
}

Topically applied camphor elicits a sensation of cool, but nothing is known about how it affects cold temperature sensing. We found that camphor sensitizes a subpopulation of menthol-sensitive native cutaneous nociceptors in the mouse to cold, but desensitizes and partially blocks heterologously expressed TRPM8 (transient receptor potential cation channel subfamily M member 8). In contrast, camphor reduces potassium outward currents in cultured sensory neurons and, in cold nociceptors, the cold-sensitizing effects of camphor and menthol are additive. Using a membrane potential dye-based screening assay and heterologously expressed potassium channels, we found that the effects of camphor are mediated by inhibition of $\mathrm{K}_{\mathrm{v}} 7.2 / 3$ channels subtypes that generate the M-current in neurons. In line with this finding, the specific M-current blocker XE991 reproduced the cold-sensitizing effect of camphor in nociceptors. However, the M-channel blocking effects of XE991 and camphor are not sufficient to initiate cold transduction but require a cold-activated inward current generated by TRPM8. The cold-sensitizing effects of XE991 and camphor are largest in high-threshold cold nociceptors. Low-threshold corneal cold thermoreceptors that express high levels of TRPM8 and lack potassium channels are not affected by camphor. We also found that menthol—like camphor—potently inhibits $\mathrm{K}_{\mathrm{v}} 7.2 / 3$ channels. The apparent functional synergism arising from TRPM8 activation and M-current block can improve the effectiveness of topical coolants and cooling lotions, and may also enhance TRPM8-mediated analgesia.

\section{Introduction}

Camphor is a ketone originally isolated from the Cinnamomum camphora tree with a penetrating characteristic odor and pun-

Received April 5, 2013; revised Sept. 2, 2013; accepted Sept. 5, 2013.

Author contributions:I.V., F.T., E.B., A.P., M.N., R.J.L., C.B., C.A., T.H., V.V.,P.W.R., and K.Z. designed research;I.V., A.H., S.S., S.H., E.B., A.P., M.N., F.T., U.H., A.L., S.B., and K.Z. performed research; I.V. and R.J.L. contributed unpublished reagents/analytic tools; I.V., A.H., S.S., S.H., F.T., E.B., A.P., U.H., A.L., S.B., M.N., V.V., T.H. and K.Z. analyzed data; I.V., T.H., and K.Z. wrote the paper.

We thank John B. Davis, GlaxoSmithKline, Harlow, UK, for donation of the breeding pairs of TRPV1 ${ }^{-1-}$ mice; and A. Dhaka and A. Patapoutian for breeding pairs of TRPM8 ${ }^{-1-}$ mice.rTRPM8 CDNA was provided by David Julius (University of California, San Francisco, San Francisco, CA); and hTRPM8 CDNA was a kind gift from Thomas Voets (K.U. Leuven, Leuven, Belgium); TRESK cDNA (Egenberger et al., 2010) was provided by Erhard Wischmeyer and Frank Döring (Department of Physiology, University of Würzburg, Würzburg, Germany); and K 7.2 and K 7.3 CDNA (Schroeder et al., 1998) was provided by Thomas Jentsch (Institute of Molecular Pharmacology, Max Delbrück Center, Berlin, Germany). TRAAK, TREK1, and TREK2 cDNA was provided by Florian Lesage (CNRS, Sophia Antipolis, France). Iwona Izydorczyk, Annette Kuhn, and Jana Schramm provided expert technical assistance with tissue culture and animal breeding/genotyping. Funding for this project was obtained through the German Research Council (DFG): Zi1172/1-1 (K.Z.), Zi1172/2-1 (K.Z., P.W.R.) and KF0130/TP7 (P.W.R.), the Dr Ernst und Anita Bauer-Foundation (S.S.), the Erika Giehrl-Foundation (F.T.), the STAEDTLER Foundation (K.Z., P.W.R.), the Australian Research Council ARC LIEF grant for the FLIPR TETRA (R.J.L.), a National Health and Medical Research Council Project Grant (I.V.), and the G08 Australia-Germany Joint Research Co-operation Scheme (I.V., K.Z.).

*I.V., A.H., S.S., and S.H. contributed equally to this work as first authors.

The authors declare no competing financial interests.

Correspondence should be addressed to Dr. Katharina Zimmermann, Department of Physiology and Pathophysiology, Friedrich-Alexander-Universität Erlangen-Nürnberg, 91054 Erlangen, Germany. E-mail: katharina.zimmermann@fau.de.

S. Sattler's present address: Department of Biomedical Sciences, The University of Sheffield, Sheffield S10 2TN, UK. M. Nissen's present address: Department of Pediatric Surgery, Ruhr University Bochum, 44627 Herne, Germany. DOI:10.1523/JNEUROSCI.1473-13.2013

Copyright $\odot 2013$ the authors $\quad 0270-6474 / 13 / 3316627-15 \$ 15.00 / 0$ gently aromatic taste. It has a long-standing medicinal use as an ingredient in analgesic creams and cooling lotions, and is used for its scent as flavoring in India and Europe. It belongs to the group of plant-derived natural compounds, such as capsaicin, menthol, zingerone, and others, that act on members of the family of thermosensitive transient receptor potential (TRP) channels (Xu et al., 2006). These receptors are purported to be involved in the conversion of thermal information into electrical signals (Clapham and Miller, 2011).

Camphor exerts agonist and desensitizing effects on TRPV1 (TRP subfamily V, member 1 ) that may account for its pungency, counterirritant, and analgesic effects (Xu et al., 2005). In addition, camphor is an agonist at the keratinocyte warm sensor TRPV3, which may mediate sensitization to warming of the skin (Green, 1990; Moqrich et al., 2005) and is a potent blocker of the noxious cold and irritant receptor TRPA1 (Xu et al., 2005; Macpherson et al., 2006; Karashima et al., 2009). Nevertheless, the scent and taste of camphor impart an after-sense of coolness, rather similar to that of menthol, and when topically applied to the skin it produces a feeling of cooling (Green, 1990; Sweetman, 2004). The mechanism of how camphor affects cold temperature sensing is unknown.

Cold sensing is mediated by specialized thermoreceptive and nociceptive nerve endings, some of which are equipped with the menthol receptor TRPM8 (McKemy et al., 2002; Peier et al., 2002), an essential cold sensor in mice (Bautista et al., 
Table 1. Synopsis of C-fibers: characteristics of fiber populations

\begin{tabular}{|c|c|c|c|c|c|c|c|c|}
\hline \multirow[b]{2}{*}{ Mouse strain } & \multirow[b]{2}{*}{ Number of mice } & \multirow{2}{*}{$\begin{array}{l}\text { Number of } \\
\text { fibers }\end{array}$} & \multirow[b]{2}{*}{$\mathrm{CV}(\mathrm{m} / \mathrm{s})$} & \multirow{2}{*}{$\begin{array}{l}\text { von Frey threshold } \\
(\mathrm{mN})\end{array}$} & \multicolumn{4}{|c|}{ Fiber subtypes } \\
\hline & & & & & $\mathrm{CM}$ & CMC & $\mathrm{CMCH}$ & $\mathrm{CMH}$ \\
\hline C57BL/6 & 13 & 24 & $0.38 \pm 0.10(0.25-0.63)$ & $11.4(1.4-64)$ & 5 & 5 & 9 & 5 \\
\hline $\operatorname{TRPV1}^{-1-}$ & 13 & 28 & $0.42 \pm 0.13(0.29-0.95)$ & $16(1-45.3)$ & 7 & 5 & 3 & 13 \\
\hline TRPM8 $^{+/+}$(N5F1) & 13 & 32 & $0.50 \pm 0.12(0.34-0.87)$ & $5.7(1.4-22.6)$ & 4 & 7 & 9 & 12 \\
\hline TRPM8 $^{-1-}(\mathrm{N} 5 \mathrm{~F} 1, \mathrm{~N} 4 \mathrm{~F} 3)$ & 6 (N5F1) 4 (N4F3) & 32 & $0.48 \pm 0.18(0.19-1.19)$ & $16(1.4-128)$ & 6 & 0 & 8 & 18 \\
\hline C57BL/6 & 7 & 14 & $0.52 \pm 0.15(0.36-0.9)$ & $8(1-32)$ & 3 & 6 & 2 & 3 \\
\hline C57BL/6 & 7 & 8 & $0.3 \pm 0.1(0.22-0.49)$ & $4(1-32)$ & 0 & 8 & 0 & 0 \\
\hline
\end{tabular}

Values are given as number, mean \pm SE (range), or median (range). The table lists number of mice per strain, conduction velocity (CV), von Frey threshold (mN), and mechanosensitive $\mathrm{C}-$ fibre subtypes. CM, C-Mechano; CMC, C-Mechano-Cold; CMCH, C-Mechano-Cold-Heat; CMH, C-Mechano-Heat.

2007; Colburn et al., 2007; Dhaka et al., 2007). Low-threshold cold thermoreceptors are mechanoinsensitive and abundant in the trigeminal territory (i.e., in the cornea of the eye), where they feature ongoing impulse activity at resting temperature $\left(34-35^{\circ} \mathrm{C}\right)$ and respond vigorously to small temperature reductions $\left(<0.5^{\circ} \mathrm{C}\right)$ as a result of high TRPM8 expression (Parra et al., 2010). TRPM8 is also present in cutaneous nociceptive and thermoreceptive nerve endings. Mechanoinsensitive skin thermoreceptors share some of the characteristics of low-threshold corneal thermoreceptors, but display a much broader range of activation thresholds $\left(37-17^{\circ} \mathrm{C}\right.$; Zimmermann et al., 2011), likely reflecting a diverging ion channel composition and function.

Apart from transducing inward currents, cold-induced closure of outward potassium channels, like $\mathrm{K}_{2} \mathrm{P}$, contributes to cold-induced depolarization (Reid and Flonta, 2001; Viana et al., 2002; Noël et al., 2009), because it increases membrane resistance and reduces the effective voltage change required to excite sensory nerve endings (Zimmermann et al., 2007). In addition, $\mathrm{K}_{\mathrm{V}} 1$ family potassium channels are coexpressed with TRPM8 and contribute to the setting of the temperature threshold in cultured trigeminal and somatic neurons (Madrid et al., 2009; Teichert et al., 2012).

To gain novel insight into cold transduction mechanisms, we investigated the molecular mechanism of how camphor induces sensitization to cooling. We used extracellular and patch-clamp electrophysiology in combination with transgenic mice, calcium imaging, and a high-throughput FLIPR Tetra-based screening assay and present the first evidence of an involvement of $\mathrm{K}_{\mathrm{V}} 7.2 / 3$ channels, which form the neuronal M-current, in the suprathreshold amplification of TRPM8-dependent cold transduction in cutaneous cold nociceptors.

\section{Materials and Methods}

Animals. C57BL/6J mice (16 females and 37 males), TRPV1 ${ }^{-1-}$ (5 females and 8 males), TRPM $8^{-1-}$ (16 males), heterozygous TRPM $8^{\text {EGFPf/+ }}$ mice (6 males), and TRPM $8^{+/+}$age-matched littermates (14 males) weighing between 18 and $32 \mathrm{~g}$ were killed by $100 \% \mathrm{CO}_{2}$. Animals were conventionally genotyped using commercially available primers (Metabion). TRPV1 $1^{-1-}$ mice were congenic to and matched with C57BL/6/J and were a gift from J.B. Davis (GSK, Harlow, UK). The primer sequences were for $w t$ CAT GGC CAG TGA GAA CAC CAT GG and AGC CTT TTG TTC TTG GCT TCT CCT; and for the knock-out allele CCG GTG CCC TGA ATG AAC T and AAG ACC GGC TTC CAT CCG A. TRPM $8^{-1-}$ and TRPM $8^{E G F P f /+}$ were donated by A. Patapoutian and A. Dhaka (The Scripps Research Institute, La Jolla, CA). TRPM8 transgenic mice were from N4F3 $(n=4)$ and N5F1-F6 $(n=12)$ generation, and littermates of the N5F1/F5 generation were matched as a control. The primer sequences were $5^{\prime}$-GGG ATG TCA TAG TGC TGA AAG for the wild-type allele, and 5'-CCG GGT GCT GCC CAT AGT ACC for the knock-out allele.
Table 2. Synopsis of C-fibers: treatment with cooling compounds menthol and camphor or M-channel modulators XE991 and retigabine

\begin{tabular}{|c|c|c|c|c|c|}
\hline Compound & Mouse strain & $\begin{array}{l}\text { All treated } \\
\text { (cold-sensitive) }\end{array}$ & $\begin{array}{l}\text { All } \\
\text { sensitized }\end{array}$ & $\begin{array}{l}\text { Sensitized cold- } \\
\text { sensitive }\end{array}$ & $\begin{array}{l}\text { Sensitized cold- } \\
\text { insensitive }\end{array}$ \\
\hline Menthol & C57BL/6 & $24(14)$ & $8(33 \%)$ & $4(29 \%)$ & $4(40 \%)$ \\
\hline \multirow[t]{4}{*}{ Camphor } & $\begin{array}{l}\text { C57BL/6 and } \\
\text { TRPV1 } 1^{+/+}\end{array}$ & $38(11)$ & $11(29 \%)$ & $4(40 \%)$ & $7(25 \%)$ \\
\hline & TRPV $1^{-1-}$ & $28(8)$ & $9(32 \%)$ & $3(38 \%)$ & $6(30 \%)$ \\
\hline & TRPM8 $^{+/+}$ & $32(16)$ & $6(19 \%)$ & $4(25 \%)$ & $2(13 \%)$ \\
\hline & TRPM8 $8^{-1-}$ & $32(8)$ & $2(6 \%)$ & $1(13 \%)$ & $1(4 \%)$ \\
\hline \multirow[t]{3}{*}{ XE991 } & C57BL/6 & $14(10)$ & $7(47 \%)$ & $7(64 \%)$ & - \\
\hline & TRPM8 $8^{-1-}$ & $22(8)$ & - & - & - \\
\hline & TRPM8 $^{+/+}$ & $2(2)$ & 2 & 2 & - \\
\hline $\begin{array}{l}\text { Menthol } \pm \text { retigabine/ } \\
\quad \text { XE991 }\end{array}$ & C57BL/6 & $8(8)$ & 8 & 8 & - \\
\hline
\end{tabular}

For details see text and materials and methods.

Single-fiber recordings. The isolated skin-saphenous nerve preparation and single-fiber recording technique were used as previously described (Zimmermann et al., 2009). The skin was kept under laminar superfusion of carbogen-gassed synthetic interstitial fluid (SIF). Receptive fields of identified mechanosensitive C-fibers were characterized with von Frey filaments and with respect to thermal responsiveness (heating and cooling). Therefore, the receptive fields were isolated from the surrounding fluid with an aluminum or Teflon ring (volume, 300-400 $\mu$ l), and kept continuously perfused with camphor, menthol, capsaicin, retigabine, XE991, or combinations of those at a rate of $10 \mathrm{ml} / \mathrm{min}$ at $30^{\circ} \mathrm{C}$. To apply prewarmed solutions as well as heat and cold stimuli, we used custom-made countercurrent temperature exchange application system (Zimmermann et al., 2009). Heat ramps were ramp shaped rising from a bath temperature of $30^{\circ} \mathrm{C}$ and reached $49 \pm 1.4^{\circ} \mathrm{C}$ (mean \pm $\mathrm{SD}$ ) within $20 \mathrm{~s}$ (average of $>50$ individual stimuli). The cold stimuli lasted $60 \mathrm{~s}$ and consisted of two phases, a first dynamic $\left(30-12^{\circ} \mathrm{C}\right)$ and a second static phase $\left(12-10^{\circ} \mathrm{C}\right)$, each lasting $30 \mathrm{~s}$. The cooling stimulus was linear during the first $7.5 \mathrm{~s}$ where the cooling rate reached a maximum of $1.5^{\circ} \mathrm{C} / \mathrm{s}$. The criterion for assigning heat responsiveness to a fiber was a discharge of at least 2 spikes. The criterion for assigning cold responsiveness to a fiber was adjusted to a discharge of at least 3 spikes due to the longer cold ramp (30 s). The noxious cold threshold was considered as the first spike discharged during cooling. Chemical sensitization to cold was considered when the magnitude of the response (number of spikes) and/or the peak discharge increased by $>1.5$-fold, in combination with a constant or decreased threshold temperature. The characteristics and treatments of the 200 recorded C-fibers are summarized in Tables 1 and 2.

Transfection procedure. Recombinant TRPM8 (rTRPM8; $0.5 \mu \mathrm{g} / \mu \mathrm{l}$ ) was transiently transfected in HEK293T cells by the calcium phosphate precipitation method or using Nanofectin (PAA Laboratories). A reporter plasmid (CD8-pih3m, $1 \mu \mathrm{g}$ ) was cotransfected to allow identification of transfected cells by Immunobeads (anti-CD-8 Dynabeads, Dynal Biotech). HEK293T cells were maintained in DMEM supplemented with penicillin/streptomycin $100 \mathrm{U} / \mathrm{ml}$, HEPES $25 \mathrm{~mm}$, fetal 
bovine serum 10\% (Invitrogen), and taurine $3 \mathrm{~mm}$ (Sigma-Aldrich) at $37^{\circ} \mathrm{C}$ and $5 \% \mathrm{CO}_{2}$. After the transfection procedure, cells were kept in culture dishes $(35 \mathrm{~mm})$ and used for patch-clamp experiments within 2-3 d. Plasmid DNA of recombinant $\mathrm{K}_{2} \mathrm{P}$ channels (TRESK, TRAAK, TREK1, and TREK2) and $\mathrm{K}_{\mathrm{V}} 7$ channels $\left(\mathrm{K}_{\mathrm{V}} 7.2\right.$ and $\mathrm{K}_{\mathrm{V}}$ 7.3) were transfected using Nanofectin (PAA Laboratories) or Fugene HD (Roche). Twenty-four hours after transfection, cells were plated on 96-well plates, 384-well plates, or glass coverslips as required and used 12 24 $\mathrm{h}$ after plating.

$D R G$ culture. Adult mice were killed by $\mathrm{CO}_{2}$ inhalation. DRGs from all spinal levels were removed and incubated in $0.6 \mathrm{mg} / \mathrm{ml}$ collagenase (type $\mathrm{XI}$, Sigma) and $3 \mathrm{mg} / \mathrm{ml}$ protease (Sigma) for $40 \mathrm{~min}$ at $37^{\circ} \mathrm{C}$ in DMEM. The ganglia were then gently triturated, and neurons were plated onto borosilicate glass coverslips, which had been treated with poly-D-lysine $(0.1 \mathrm{mg} / \mathrm{ml}$ for $30 \mathrm{~min})$ and cultured $\left(37^{\circ} \mathrm{C}, 5 \% \mathrm{CO}_{2}\right.$ in air $)$ in serum-free TNB-100 basal medium (Biochrom AG), supplemented with penicillin, streptomycin, and $100 \mathrm{ng} / \mathrm{ml}$ nerve growth factor-7S (Alomone Labs). Recordings were made after $\sim 24 \mathrm{~h}$ in culture.

Patch-clamp electrophysiology. Whole-cell patch-clamp recordings were conducted at room temperature $\left(\sim 21^{\circ} \mathrm{C}\right)$ with an Axopatch $200 \mathrm{~B}$ amplifier and the pClamp 10 software (both Molecular Devices) installed on a conventional PC. Patch-clamp pipettes with a final resistance of 1.5-3 $\mathrm{M} \Omega$ were fabricated with borosilicate capillary glass (TW150F-3, World Precision Instruments). Currents were sampled at $2-5 \mathrm{kHz}$ and filtered at $1 \mathrm{kHz}$. Voltage-clamp recordings were made on HEK293T cells and on small and medium-sized DRG neurons from a holding potential of $-60 \mathrm{mV}$. Current-clamp recordings were made on small- and medium-sized DRG neurons from TRPM $8^{\text {EGFPf/+ }}$ neurons and nonfluorescent neurons, only including cells with a resting potential negative to $-47 \mathrm{mV}$. Only one cell per dish (HEK293T cells) or coverslip (DRG neurons) was used. The standard extracellular solution contained the following (in mM): $\mathrm{NaCl} 140, \mathrm{KCl} 3, \mathrm{CaCl}_{2} 1, \mathrm{MgCl}_{2} 1$, HEPES 10, and glucose 20, adjusted to $\mathrm{pH} 7.4$ with $\mathrm{NaOH}$. The pipette solution for current-clamp experiments contained the following (in $\mathrm{mM}$ ): K-Gluconate 135, $\mathrm{NaCl} 4, \mathrm{MgCl}_{2}$ 3, Na-GTP 0.3, $\mathrm{Na}_{2}$-ATP 2, EGTA 5, and HEPES 5, adjusted to $\mathrm{pH} 7.25$ with $\mathrm{KOH}$. The internal solution for recording of $\mathrm{K}_{2} \mathrm{P}$ channels in HEK cells contained the following (in $\mathrm{mM}$ ): $\mathrm{KCl} 150, \mathrm{MgCl}_{2}$ 3, HEPES 10, and EGTA 5, adjusted to $\mathrm{pH} 7.2$ with $\mathrm{KOH}$. The thermal stimuli were delivered using a multichannel, gravity-driven perfusion system incorporating rapid-feedback temperature control and consisted of heating (to $\sim 45^{\circ} \mathrm{C}$ ) and respective cooling (to $\sim 15-10^{\circ} \mathrm{C}$ ) of the test solution were applicable (Dittert et al., 2006).

Recordings of $K_{V} 7.2, K_{V} 7.3$, and TRPM8. HEK293T cells were plated on $3.5 \mathrm{~cm}$ dishes $1 \mathrm{~d}$ before transfection with Nanofectin (PAA Laboratories) according to the manufacturer's protocol using $1 \mu \mathrm{g}$ of cDNA of human $\mathrm{K}_{\mathrm{V}} 7.2$ and $\mathrm{K}_{\mathrm{V}} 7.3$, and human TRPM8 and $0.5 \mu \mathrm{g}$ of eGFP. Transfected cells were identified $2 \mathrm{~d}$ after transfection by using an inverted fluorescent microscope (Axiovert 40, Zeiss) combined with a fiber optic-coupled light source (UVICO, Rapp OptoElectronic). Whole-cell recordings were performed at room temperature $\left(\sim 21^{\circ} \mathrm{C}\right)$ using an Axopatch $700 \mathrm{~B}$ amplifier in conjunction with a Digidata 1322A interface and pClamp 10.3 software (all from Molecular Devices/MDS Analytical Technologies). Experiments were started 3 min after whole-cell access was obtained. Borosilicate glass electrodes (Biomedical Instruments) were pulled on a DMZ-Universal Puller (Zeitz) and had a tip resistance in bath solution of $2.8-4.0 \mathrm{M} \Omega$. Series resistance compensation was $\geq 75 \%$. For brief perfusion ( $1 \mathrm{~s}$ ), menthol was pressure ejected at 1 bar (PDES-02T, npi Electronic) through a pipette that was positioned in close proximity to the recorded cell. For longer perfusion of menthol, we used a gravity-driven Y-tube application system. The internal solution contained the following (in mM): K-gluconate 135, HEPES 5, $\mathrm{MgCl}_{2} 3$, EGTA 5, $\mathrm{Na}_{2}$ ATP 2, $\mathrm{Na}_{3}$ GTP 0.3 , and $\mathrm{NaCl} 4$, adjusted to $\mathrm{pH}$ of 7.25 with $\mathrm{KOH}$. External solution was composed of the following (in $\mathrm{mM}$ ): $\mathrm{NaCl}$ $145, \mathrm{KCl} 4, \mathrm{MgCl}_{2} 2, \mathrm{CaCl}_{2} 2$, HEPES 10, and D-glucose 10, adjusted to pH 7.4 with $\mathrm{NaOH}$. Puffer pipettes were filled with external solution and $50 \mu \mathrm{M}$ menthol. To determine $\mathrm{EC}_{50}$ values, dose-response data were fitted to a logistic (Boltzmann) equation of the following form:

$$
\frac{A_{1}-A_{2}}{1+\left(\frac{x}{\mathrm{EC}_{50}}\right)^{p}}+A_{2}
$$

where $A_{1}$ and $A_{2}$ are the upper and the lower asymptotes, respectively, $\mathrm{EC}_{50}$ is the half-blocking concentration, and $p$ is a power factor. Data were analyzed using pClamp 10.3 and Origin Pro9.0G Software (Origin Lab Corp.).

FLIPR $\mathrm{Ca}^{2+}$ and membrane potential blue dye assay. To assess changes in membrane potential or intracellular $\mathrm{Ca}^{2+}$ using the FLIPR Tetra (Molecular Devices) plate reader, cells were plated at a density of 10,000 cells/well on 384-well black-walled imaging plates (Corning) $24 \mathrm{~h}$ before the assay. Cells were loaded with blue membrane potential dye or Calcium 4 No-wash dye (Molecular Devices) in standard extracellular solution for $30 \mathrm{~min}$ at $37^{\circ} \mathrm{C}$ and $5 \% \mathrm{CO}_{2}$. Changes in membrane potential or $\mathrm{Ca}^{2+}$ responses were measured using a cooled CCD camera (membrane potential: excitation, $510-545 \mathrm{~nm}$; emission, $515-575 \mathrm{~nm}$; $\mathrm{Ca}^{2+}$ responses: excitation, $470-495 \mathrm{~nm}$; emission, $515-575 \mathrm{~nm}$ ) for $300 \mathrm{~s}$ after the addition of menthol, XE991, retigabine, or camphor. Raw fluorescence data were analyzed using Screenworks 3.1.1.4 (Molecular Devices) and fitted using GraphPad Prism (version 4.00). The dose-response data were fitted to a four-parameter Hill equation with variable Hill slope of the following form:

$$
Y=A_{2}+\frac{A_{1}-A_{2}}{1+10^{\left(\mathrm{Log} \mathrm{EC}_{50}-X\right) \times \text { Hill slope }}}
$$

where $A_{1}$ and $A_{2}$ represent the maximal and minimal values.

Calcium microfluorimetry. Calcium imaging experiments were performed as previously described (Babes et al., 2010). Dissociated mouse DRG neurons or HEK293T cells transiently transfected with rTRPM8 were plated on poly-D-lysine-coated glass coverslips and loaded with Fura-2AM $(3 \mu \mathrm{M})$ supplemented with $0.02 \%$ pluronic acid (both from Invitrogen) for $30 \mathrm{~min}$ at $37^{\circ} \mathrm{C}$ and $5 \% \mathrm{CO}_{2}$ dissolved in extracellular solution followed by a $15 \mathrm{~min}$ washout. Ratiometric calcium imaging was performed on an Olympus IX71 inverse microscope with an $20 \times$ or $10 \times$ objective at $35^{\circ} \mathrm{C}$ (DRGs) and ambient temperature (recombinant TRPM8). Fura-2AM was excited at 340 and $380 \mathrm{~nm}$ with a Polychrome V monochromator (Till Photonics). Images were exposed for $2 \mathrm{~ms}$ and acquired at a rate of 1/s with a 12-bit CCD camera (Imago Sensicam QE, Till Photonics). Data were recorded and further analyzed using TILLvisION 4.0.1.3 software (Till Photonics). To assess $\mathrm{Ca}^{2+}$ responses to cold and chemical stimulation, a software controlled six-channel gravitydriven common-outlet system was used (Dittert et al., 2006). DRGs were selected for cold sensitivity and were characterized for TRP channel expression by application of menthol $(250 \mu \mathrm{M})$. Recombinant TRPM8 was superfused with $100 \mu \mathrm{M}$ menthol. Cells were considered responsive to a stimulus when the ratio increased by at least $20 \%$ over baseline. In HEK293T cells, ionomycin $(2 \mu \mathrm{M})$ was applied to the cells at the end of the experiment.

Corneal nerve terminal impulse recordings. Recordings were performed as previously described (Parra et al., 2010). Animals were killed by exposure to $\mathrm{CO}_{2}$. Eyes were carefully removed and placed in a glass with physiological saline solution for $30 \mathrm{~min}$ at room temperature and bubbled with carbogen. The optic nerve and associated tissues were drawn into a suction tube at the bottom of the recording chamber, and the eye was continuously perfused $(1 \mathrm{ml} / \mathrm{min})$ with carbogen-gassed physiological saline solution of the following composition (in mM): $\mathrm{NaCl} 128, \mathrm{KCl}$ 5, $\mathrm{NaH}_{2} \mathrm{PO}_{4} 1, \mathrm{NaHCO}_{3} 26, \mathrm{CaCl}_{2} 2.4, \mathrm{MgCl}_{2} 1.3$, and glucose 10 . The bath temperature was kept constant $\sim 34^{\circ} \mathrm{C}$ using a custom-designed Peltier device. To record extracellular nerve terminal impulse (NTI) activity, a suction glass pipette (tip diameter, $\sim 50 \mu \mathrm{m}$ ) filled with the same physiological saline was applied to the surface of the corneal epithelium and a ground $\mathrm{Ag} / \mathrm{AgCl}$ pellet was placed inside the recording chamber. Signals were recorded using an AC amplifier (Neurolog NL104, Digitimer Ltd) with the gain set to $2 \mathrm{k}$ and the bandpass to $0.1 \mathrm{~Hz}$. Data 

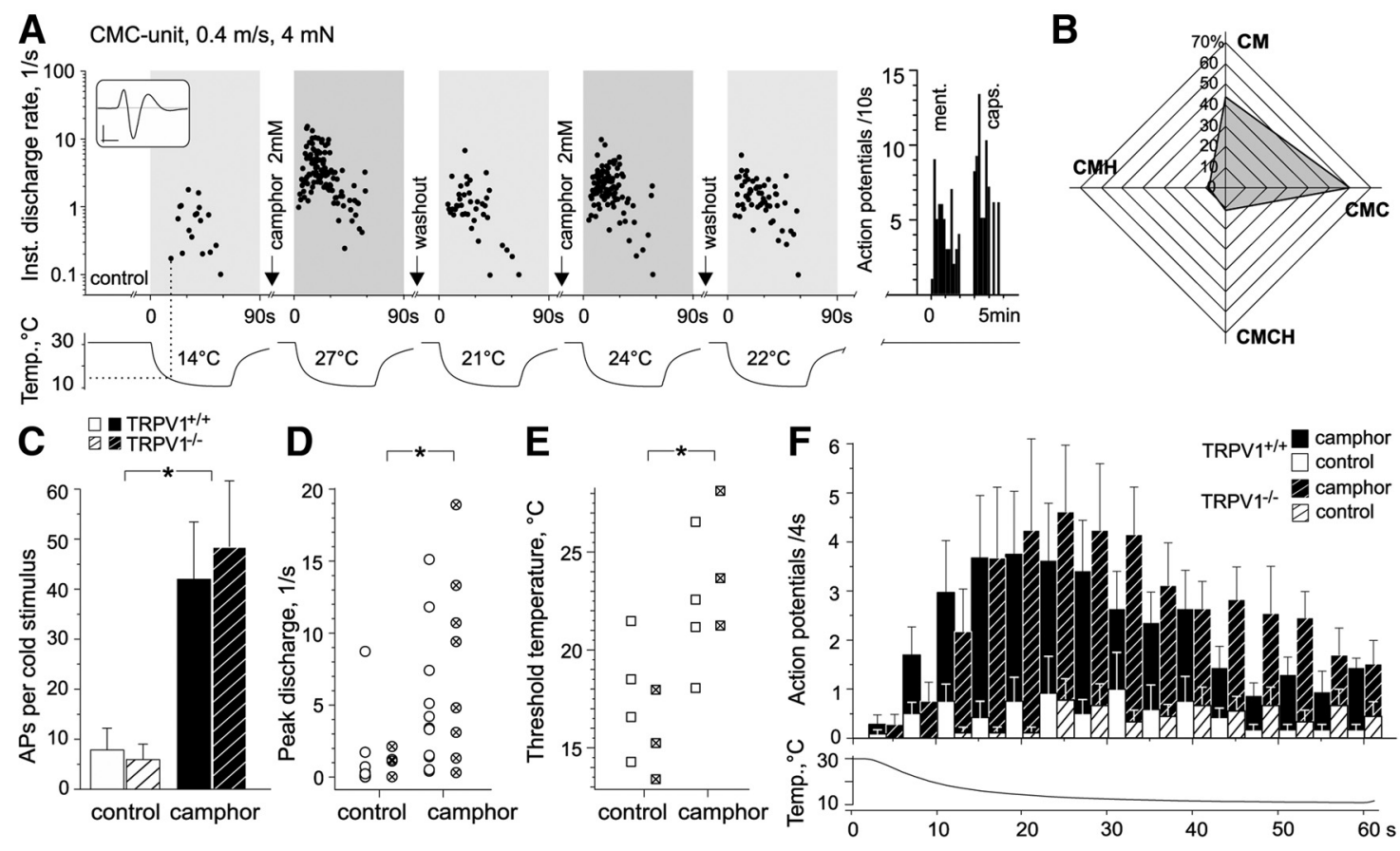

Figure 1. Camphor boosts cold transduction in a subpopulation of nociceptors. A, Original recording from a cold nociceptor showing instantaneous discharge rates in response to camphor application and cooling from $30^{\circ} \mathrm{C}$ to $10^{\circ} \mathrm{C}$. Camphor $2 \mathrm{~mm}$ superfused $5 \mathrm{~min}$ after a control cold stimulus sensitizes a menthol-and capsaicin-sensitive fiber to cooling. Interstimulus interval and drug wash-in was $5 \mathrm{~min}$. Lower trace, Time course of cold stimulus and temperature thresholds of activation. Note the shift in activation threshold induced by camphor. Inset, Average spike shape. Calibration: $0.5 \mathrm{~ms}, 200 \mu \mathrm{V}$. B, Four-way distribution describing the percentage of mechanosensitive C-fibers of each subclass sensitized to cold by camphor (CM, temperature-insensitive nociceptor, $n=12 / 26$; $(M C$, cold nociceptor, $n=6 / 10) ;(M C H$, multimodal nociceptor, $n=1 / 9 ;(C M H$, polymodal nociceptor, $n=1 / 21) ;$ all, $n=20 / 66)$. C $E$, Quantification of the sensitization of camphor to cold: increase in response magnitude counted as action potentials (APs) per $60 \mathrm{~s}$ of cold stimulus (white bars: wild type, $7.6 \pm 4.5-41.8 \pm 11.6, p<0.004 ;$ striped bars: TRPV1 ${ }^{-/-}, 5.9 \pm$ $3.1-48.3 \pm 13.2 ; p<0.008$, Wilcoxon test; no difference between genotypes, $U$ test; $C$ and peak firing frequency (open circles: wild type, $1.1 \pm 0.7-4.9 \pm 1.4$ spikes/s; $($ rossed circles: TRPV1 ${ }^{-1-}, 0.5 \pm 0.3-7.2 \pm 2.8$ spikes $/ s ; p<0.008$, Wilcoxon test; $n$ no difference between genotypes, $U$ test; $\boldsymbol{D}$ ], and rise in threshold temperature in sensitized cold-sensitive units [open rectangles: wild type, $17.7 \pm 1.5^{\circ} \mathrm{C}-22.1 \pm 1.8^{\circ} \mathrm{C}$ (only $\left.\mathrm{CMCH}, n=4\right)$ ); crossed rectangles: $\operatorname{TRPV} 1^{-/-}, 15.5 \pm 0.9^{\circ} \mathrm{C}-24.3 \pm 1.8^{\circ} \mathrm{C}$ (only CMC, $n=3$ ), significant for pooled population, $p<0.03$, Wilcoxon test; $n$ o difference between genotypes, $U$ test; $\boldsymbol{E}] . F$, Averaged histogram summarizing the cold responses of all sensitized nociceptors in bins of $4 \mathrm{~s}(n=20)$ for $T R P V 1^{-1-}($ striped white and black bars) and TRPV1 ${ }^{+/+}$(blank white and black bars), camphor 2 mm induced sensitization to cold in one-third of the treated fibers (TRPV1 ${ }^{+/+}, n=11 / 38$; and $\left.T_{R P V}{ }^{-I-}, n=9 / 28\right)$. TRPV ${ }^{+/+}$were congenic to $\mathrm{C57BL} / 6$. Lower trace, Temperature time course.

capture was performed with the CED 1401 interface and the Spike2 6.0 software (Cambridge Electronic Design). Cold thermoreceptor endings were identified by their characteristic ongoing, often regular, lowfrequency impulse activity at $34^{\circ} \mathrm{C}$, which increased during cooling and silenced in response to warming. Ongoing NTI activity at $34^{\circ} \mathrm{C}$ was recorded for at least $1 \mathrm{~min}$ before cooling. Basal mean ongoing activity (impulses per $1 \mathrm{~s}$ ) was calculated during the $30 \mathrm{~s}$ preceding the onset of a $30 \mathrm{~s} \mathrm{ramp}$-like temperature drop to $20^{\circ} \mathrm{C}$ at a rate of $0.65 \pm 0.02^{\circ} \mathrm{C} / \mathrm{s}$. This protocol was repeated after exposure to camphor. Cooling thresholds are temperature values in degree Celsius at which NTI frequency increased to a value that was the mean NTI frequency, measured during the $10 \mathrm{~s}$ period that preceded the onset of a cooling ramp, plus three times its SD. Peak frequency values are the maximal impulse per second rate of NTI frequency during the cooling ramp. The slope ( $\Delta$ rate/ $\Delta$ temperature; impulses per second per degree Celsius) is the slope of the line between the firing frequency at the cooling threshold and the peak frequency per second value, related to the temperature in degrees Celsius.

Compounds. Camphor, menthol, XE991 [10,10-bis (4-pyridinylmethyl)-9(10H)-anthracenone], and capsaicin were purchased from Sigma. Retigabine was purchased from Alomone Labs. Camphor was used at a final concentration of 1,2 , or $10 \mathrm{~mm}$, diluted from a $2 \mathrm{~m}$ stock in ethanol. Menthol was dissolved in ethanol and kept deep frozen at $10 \mathrm{~mm}$ until dissolved in SIF to $50 \mu \mathrm{M}, 100 \mu \mathrm{M}, 250 \mu \mathrm{M}$, or $0.5 \mathrm{~mm}$. Capsaicin was dissolved in ethanol to a concentration of $10 \mathrm{~mm}$ and stored deep frozen until used at a concentration of $1 \mu \mathrm{M}$. XE991 was found to be unstable in frozen stock and in solution. Therefore, stock was prepared fresh from powder at $10 \mathrm{~mm}$ using DMSO before each experiment and kept refrigerated. For each recording, a new solution at a final concentration of 10 or $100 \mu \mathrm{M}$ was prepared from the refrigerated stock. The same procedure was followed for retigabine, which was dissolved in DMSO at a concentration of $10 \mathrm{~mm}$ and used at a final concentration of $50 \mu \mathrm{M}$.

Statistical analysis. Unless otherwise stated, the Wilcoxon matchedpairs test was used for intraindividual comparisons. Differences were considered statistically significant at $p<0.05$. For analysis, Statistica version 6 (StatSoft) was used. All data in figures are expressed as the mean \pm SEM; in tables, they are expressed as SE.

\section{Results}

\section{Camphor boosts cold transduction in cutaneous nerve} endings with functional TRPM8

We attempted to characterize the subpopulations of sensory neurons that are camphor sensitive using the isolated mouse skinnerve preparation (Zimmermann et al., 2009). We applied camphor focally to the receptive field of sensory nerve endings to record the propagated action potentials in response to cooling. We found that $2 \mathrm{~mm}$ camphor sensitized 25-30\% of mechanosensitive C-fibers strikingly to cold (Fig. 1); a $2 \mathrm{~mm}$ dose is likely to be a medicinally relevant concentration, because camphor used in ointments and other topical preparations is present at up to $11 \%$, which may correspond to several hundred millimolar camphor intracutaneously (Xu et al., 2005). Because camphor was previously identified as a TRPV1 agonist (Xu et al., 2005), we included recordings from TRPV1-deficient animals (Davis et al., 2000). We found similar cold-sensitizing effects in both genotypes (Fig. 1C-F); the cold sensitization of camphor became manifest in a several-fold increase in cold-activated action poten- 
A $\quad$ CM-unit, $0.33 \mathrm{~m} / \mathrm{s}, 8 \mathrm{mN}$

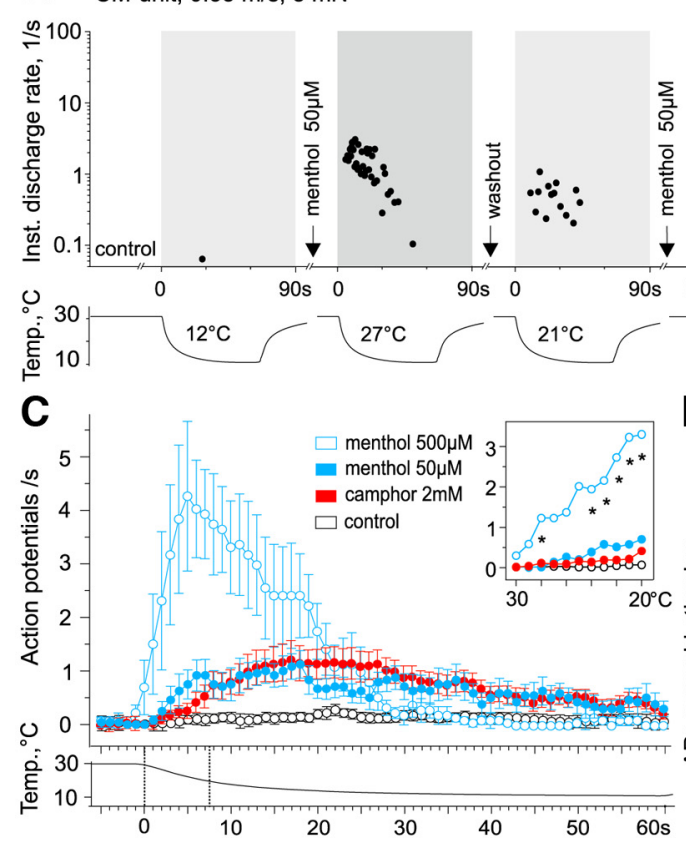

B

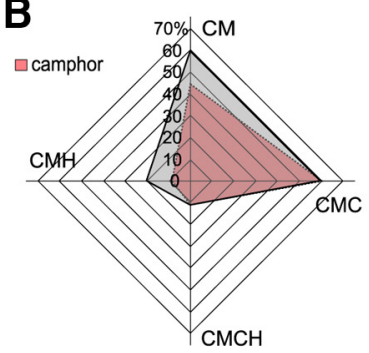

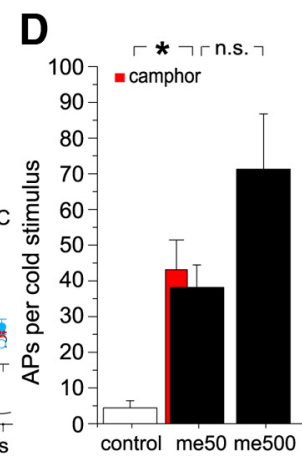
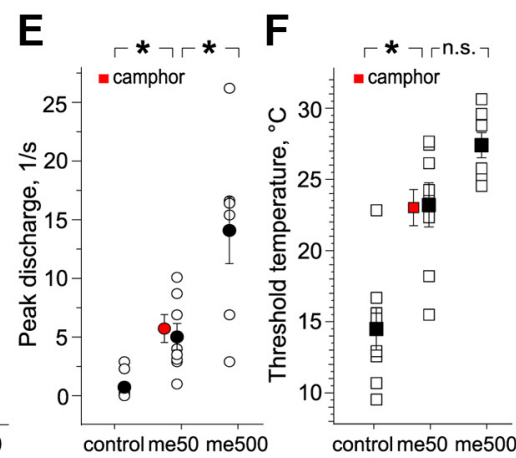

Figure 2. Cold sensitization by camphor overlaps with sensitivity to menthol. $A$, Original recording from a temperature-insensitive nociceptor showing instantaneous discharge rates in response to menthol application and cooling. Menthol produced de novo, partly reversible, reproducible, and concentration-dependent sensitization to cold. Interstimulus interval and drug wash-in was 5 min. Lower trace, Time course of cold stimulus and temperature thresholds of activation. B, Four-way distribution describing the percentage of mechanosensitive $C$-fibers of each subclass sensitized to cold by menthol (CM, temperature-insensitive nociceptor, $n=3 / 5 ; \mathrm{CMC}$, cold nociceptor, $n=3 / 5 ; \mathrm{CMCH}$, multimodal nociceptor, $n=1 / 9 ; \mathrm{CMH}$, polymodal nociceptor, $n=1 / 5 ;$ all, $n=8 / 24$; red area: fibers sensitized to cold by camphor projected from Figure 1B). $C$, Averaged histogram (1 s bins, three-point adjacent averaging) comparing cold-sensitizing effects of menthol (closed blue circles, $50 \mu \mathrm{m}$; open blue circles, $500 \mu \mathrm{m}$ ) and camphor (red closed circles, pooled data from both genotypes in Fig. 1F); control. Note that a higher concentration of menthol leads to greater dynamic activation and inactivation (adaptation) by cooling. Inset, Stimulus response diagram (APs $\left./{ }^{\circ} \mathrm{C}\right)$ for the first linear $7.5 \mathrm{~s}$ of the cold stimulus $\left(1.5^{\circ} \mathrm{C} / \mathrm{s}\right.$, corresponding to the time interval defined by dotted lines in lower trace). The difference between both menthol concentrations was significant during the falling phase of temperature (asterisks represent $p<0.04$, Wilcoxon test). $\boldsymbol{D}-\boldsymbol{F}$, Quantification of menthol sensitization to cold: increase in response magnitude (control, $4.4 \pm 2.0 ; 50 \mu \mathrm{m}, 38.1 \pm 6.3 ; 500 \mu \mathrm{m}, 71.3 \pm 15.5 ; n=8 / 8 / 7 ; p=0.01$ and $p=0.09$, Wilcoxon test; D) and in peak firing frequency (control, $0.7 \pm 0.4 ; 50 \mu \mathrm{m}, 5.0 \pm 1.1 ; 500 \mu \mathrm{m}, 14.1 \pm 2.8 \mathrm{spikes} / \mathrm{s} ; n=8 / 8 / 7 ; p=0.01$ and $p=0.02$, Wilcoxon test; $\boldsymbol{E}$ ), and a rise in threshold temperature (control, $14.4 \pm 1.5^{\circ} \mathrm{C} ; 50 \mu \mathrm{M}, 23.2 \pm 1.6^{\circ} \mathrm{C} ; 500 \mu \mathrm{M}, 26.1 \pm 1.6^{\circ} \mathrm{C} ; n=8 / 8 / 7 ; p=0.03$ and $p=0.09$, respectively, Wilcoxon test; $\left.\boldsymbol{F}\right)$. Solid symbols represent the mean. Note that camphor $2 \mathrm{~mm}$ and menthol $50 \mu \mathrm{m}$ produce equipotent cold-sensitizing effects in all three measures of sensitization (red projections in $\boldsymbol{D}-\boldsymbol{F}$ represent pooled data from both genotypes shown in Fig. 1C-E).

tial discharge and was accompanied by a large rise in peak firing frequency and a drop in activation threshold by $5^{\circ} \mathrm{C}($ Fig. $1 C-E)$. The camphor-induced sensitization to cold was partially reversible within 5 min of washout, and repeated applications produced comparable responses (Fig. 1A). Remarkably, camphor sensitized less than half of the cold-sensitive nociceptors to cold $(\sim 40 \%)$, and mostly C-Mechano-Cold (CMC) fibers (Table 1; Fig. 1B). Cold transduction in CMC fibers depends on TRPM8, because we previously demonstrated that these fibers are lacking in TRPM8-deficient mice (Zimmermann et al., 2011). In addition, camphor induced novel pronounced responsiveness to cold in some of the thermoinsensitive nociceptors [CMechano (CM); Table 1; Fig. 1B].

To elucidate the molecular mechanism of the cold-sensitizing effects of camphor, we first compared cold sensitization by camphor with menthol and determined equipotent concentrations and the overlap of camphor- and menthol-sensitive fibers. Expectedly and similar to camphor, menthol sensitized to cold (Fig. 2), and likewise the sensitization (to $50 \mu \mathrm{M}$ ) consisted in a severalfold increase in the magnitude of the cold response, a large rise in peak firing frequency, and a large drop in threshold temperature, depending on the concentration (using 50 and $500 \mu \mathrm{M}$; Fig. 2D$F$ ). Like camphor, this effect was largely reversible (Fig. $2 A$ ) and mainly affected $\mathrm{CMC}$, but also some of the $\mathrm{CM}$ nociceptors, where de novo responsiveness to cold occurred. Polymodal [C-Mechano-Heat $(\mathrm{CMH})]$ or multimodal nociceptors [CMechano-Cold-Heat $(\mathrm{CMCH})]$ were not affected (Table 1, Fig.
$2 B$ ). In contrast to previous patch-clamp reports from cultured rat DRG neurons (Reid et al., 2002), where all neurons with coldactivated inward current were menthol sensitive, and with calcium imaging (Babes et al., 2004; Bautista et al., 2006), where the majority $(\sim 70 \%)$ of cold-sensitive cells displayed menthol sensitivity, menthol sensitized only $30 \%$ of the murine native coldsensitive terminals (Fig. 2B, CMC and $\mathrm{CMCH}$ ). Remarkably, the higher concentration of menthol $(500 \mu \mathrm{M})$ not only led to a greater and more dynamic activation by cooling, but also to a greater inactivation (adaptation) during the second, static, period of cold stimulation (Fig. $2 A, C$ ). Accordingly, the difference between both menthol concentrations reached significance only during the falling phase of temperature when the cooling rate was maximal $\left(-1.5^{\circ} \mathrm{C} / \mathrm{s}\right.$, from $30^{\circ} \mathrm{C}$ to $20^{\circ} \mathrm{C}$; Fig. $2 \mathrm{C}$, inset). Comparing camphor and menthol, we found that $50 \mu \mathrm{M}$ (menthol) and 2 $\mathrm{mm}$ (camphor) produced not only a very similar pattern of cold sensitization (Fig. 2C), but were equipotent in all three measures of sensitization (Fig. $2 D-F$, red projections; data pooled from both genotypes TRPV1 $1^{-/-}$and TRPV1 ${ }^{+/+}$), magnitude of cold response, peak discharge, and shift in threshold temperature.

\section{Camphor transiently activates, desensitizes, and blocks TRPM8}

We tested next whether camphor modulates cold transduction by directly targeting the menthol receptor TRPM8. Therefore, we heterologously expressed rTRPM8 in HEK293T cells and used calcium microfluorimetry. Using the FLIPR Tetra plate reader to 
A rTRPM8 HEK293t
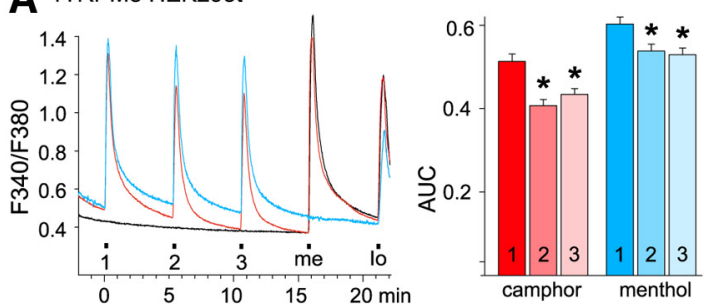

C I cold $_{\text {rTRPM8 HEK293t }}$
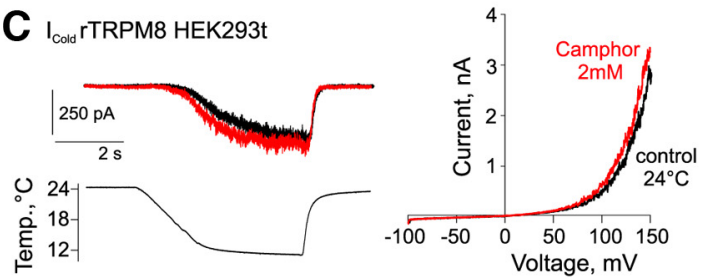

B
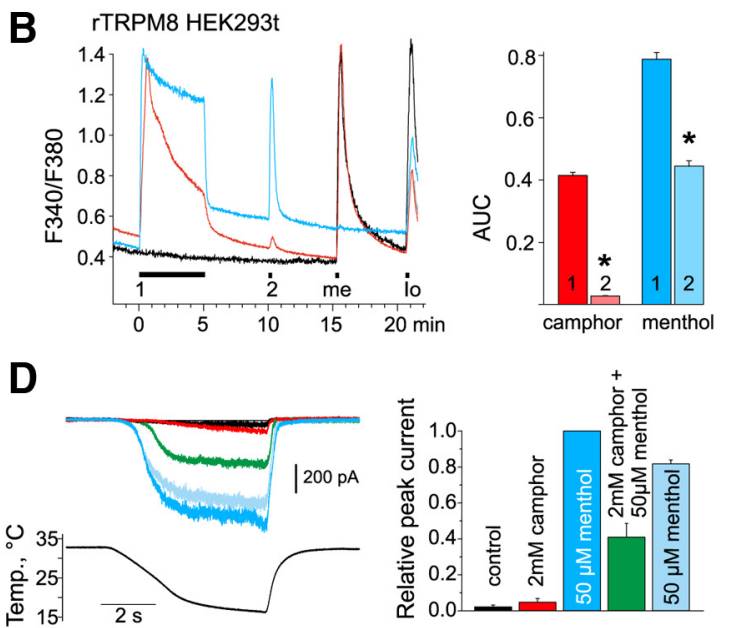

E

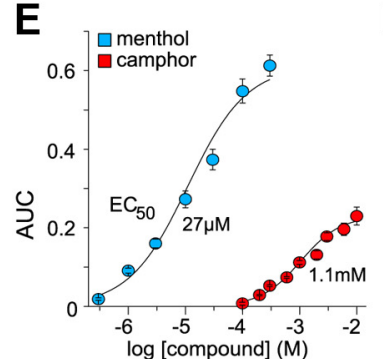

$\mathbf{F}$

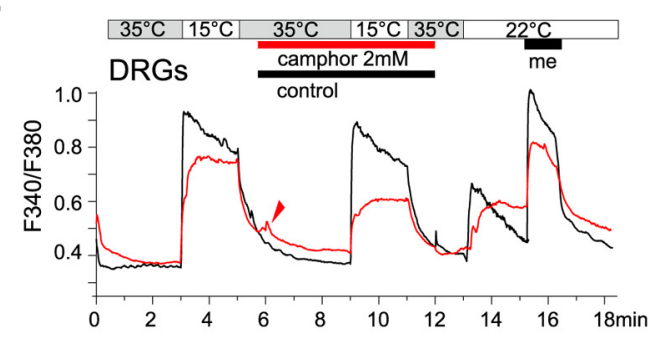

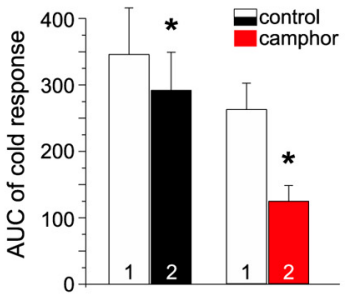

Figure 3. Camphor exerts mixed agonist and antagonist effects on recombinant rTRPM8. $A, B$, Average response of HEK293T cells $(n=100)$ transiently transfected with rTRPM8 and submitted to repetitive short (three consecutive applications of 15 s each, numbered $1-3 ; \boldsymbol{A}$ ) and one longer ( 5 minfollowed by $15 \mathrm{~s}$ ) stimulation with camphor ( $2 \mathrm{~mm}$; red) or menthol (100 $\mu \mathrm{Mm}$; blue; $\boldsymbol{B})$; bar charts on the right illustrate the area under the curve (AUC) of consecutive responses. Menthol was applied after camphor applications to test for heterologous desensitization (red, but not blue lines). Black lines, Control menthol responses. Note that long application of camphor-induced potent homologous but not heterologous desensitization. C, Cold-activated inward currents in HEK293T cells transiently transfected with rTRPM8. Camphor applied alone or in combination with a cold stimulus had no effect on the cold-induced current through TRPM8. $I_{\text {cold }}$ through TRPM8 reached an average peakamplitude of $273 \pm 73 \mathrm{pA}\left(n=8\right.$; cold-stimulus to $\left.\sim 10^{\circ} \mathrm{C}\right)$ and of $304 \pm 78 \mathrm{pA}$ in the presence of camphor $\left(n=8 ; p>0.05\right.$, Student's paired $t$ test). Right trace, TRPM 8 activation at $24^{\circ}$ C displays a strong outward rectification during voltage ramps $(500 \mathrm{~ms})$ from -100 to $+150 \mathrm{mV}$ (lower trace); the effect of camphor $2 \mathrm{~mm}$ was verysmall. D, The 2 mu camphor partiallyblocked cold-activated currents ofheterologously expressed TRPM8 when sensitized by $50 \mu$ mmenthol. The camphor-induced inhibition of the cold-activatedand menthol-sensitized peak current reached $\sim 60 \%(n=6)$. $E$, Concentration-response relationship of camphor ( $\mathrm{EC}_{50}, 1.1 \mathrm{~mm}$ ) and menthol ( $\mathrm{EC}_{50}, 0.027 \mathrm{~mm}$ ) in HEK293T cells transiently transfected with rTRPM8 using conventional calcium imaging; asterisk signifies $p<0.001$ using unpaired $t$ test. $\boldsymbol{F}$, Effect of camphor on cold responses $(2 \mathrm{~min})$ of cold-and menthol-sensitive (me) cultured mouse DRG neurons loaded with Fura-2AM. Camphor applied after a control cold stimulus reduced the cold-activated calcium signal of the second cold stimulus by $53 \%$ (red line; mean of $n=14, p=0.006$, Wilcoxon test). Repeated superfusion with cooled extracellular solution reduced the calcium signal of the second cold stimulus in menthol-sensitive cells by $16 \%$ (dotted blackline; mean of $n=8$ cells, $p=0.025$, Wilcoxontest). Barchart (right) compares AUC for cold-activated calcium signal offirstand second cold responses. Red arrowhead, Some of the cells showed a rapid and transient calcium increase upon camphor application.

measure stimulus-induced activity of rTRPM8-expressing cells, we found that camphor, in contrast to menthol, rapidly activated and then desensitized TRPM8-mediated $\mathrm{Ca}^{2+}$ responses within 1 min of application (data not shown). Using conventional calcium imaging, we confirmed a TRPM8-activating effect and also found that application of camphor resulted in profound desensitization of the receptor. This desensitization was mild following short (15 s) applications of camphor (Fig. $3 A$ ) but was predominant with longer application periods, and it manifested only as homologous, not as heterologous, desensitization (to menthol). A 5 min lasting application of camphor-as performed in our skin-nerve experiments - desensitized the receptor within $<1$ min and reduced the amplitude of the calcium response to a second camphor application by $95 \%$ (Fig. 3B). We obtained these results also for recombinant human TRPM8 (data not shown). Using $2 \mathrm{mM}$, the camphor-activated calcium increase was blocked in the presence of the TRPM8 antagonist BCTC $10 \mu \mathrm{M}$, and it was absent in nontransfected HEK293T cells and in calcium-free external solution (data not shown). In whole-cell recordings, a comparable TRPM8-activating effect was not observed at physiologically relevant holding potentials. Camphor was without effect on cold-activated $\left(I_{\text {cold }}\right)$ TRPM8 currents. $I_{\text {cold }}$ reached an av- erage peak amplitude of $273 \pm 73 \mathrm{pA}$, and $2 \mathrm{~mm}$ camphor had no effect $\left(I_{\text {cold }} 304 \pm 78 \mathrm{pA}\right)$. The response of TRPM8 displayed a strong outward rectification during voltage ramps (500 ms) from -100 to $+150 \mathrm{mV}$ (Voets et al., 2004). Only at very positive potentials $(+140 \mathrm{mV})$ did camphor $(2 \mathrm{~mm})$ have a small potentiating effect of $15 \%(n=7, p=0.02$; Fig. $3 C)$. In contrast, camphor partially blocked inward currents through TRPM8 when the channel was activated by menthol (Fig. 3D). At $25^{\circ} \mathrm{C}, 2 \mathrm{~mm}$ camphor inhibited the peak current by $\sim 70 \%$ (data not shown). When combined with cold, camphor $(2$ $\mathrm{mm}$ ) partly inhibited the menthol-induced potentiation of the cold-activated current, but in steady state the amplitude of the current was not further reduced. At $15^{\circ} \mathrm{C}$, inhibition of peak $I_{\text {cold }}$ potentiated by $50 \mu \mathrm{M}$ menthol reached $\sim 60 \%$ and was reversible (Fig. $3 D$ ). One likely reason for the lack of a discrete inward current in whole-cell mode may be the comparatively weak TRPM8 agonism of camphor, with menthol exhibiting an $\mathrm{EC}_{50}$ of $0.027 \mathrm{mM}$, in contrast to camphor with $1.1 \mathrm{mM}$ (Fig. $3 E$ ).

We next tested the effect of camphor using calcium microfluorimetry in cultured DRGs of C57BL/6 mice loaded with Fura2AM, and we observed both transient rapid activating and 

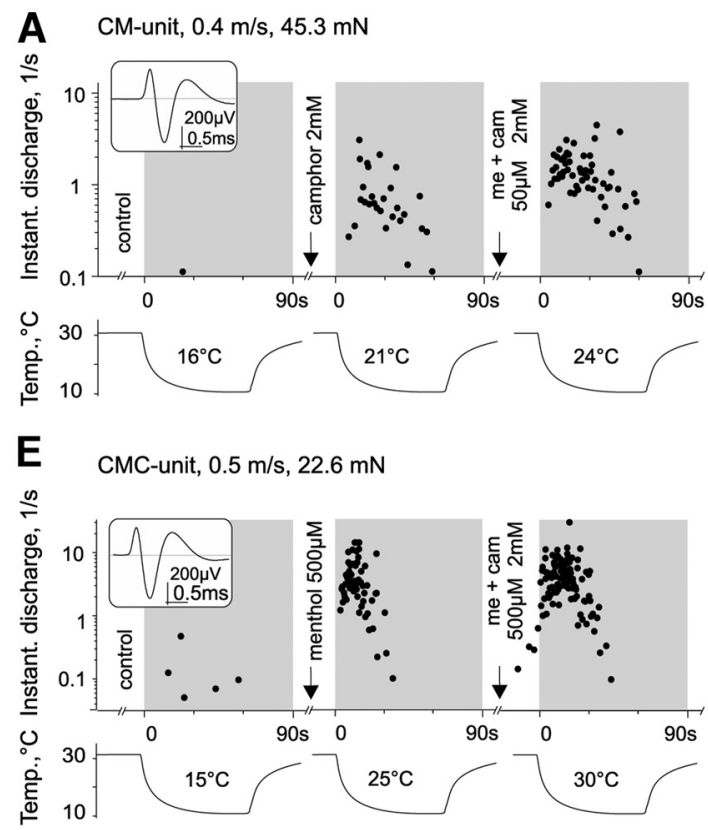

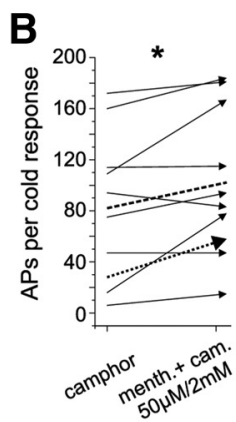

$\mathbf{F}$

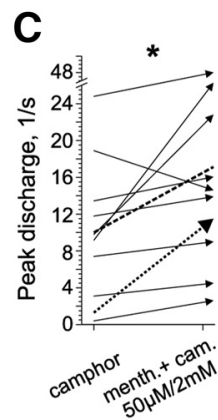

G

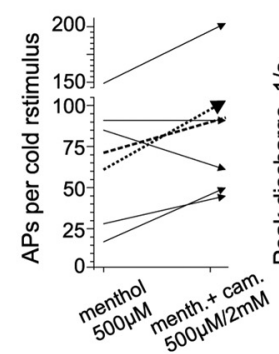

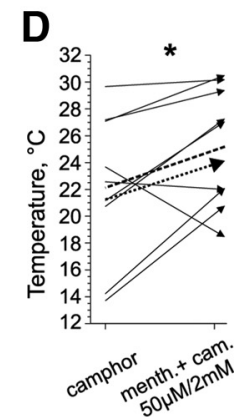

$\mathrm{H}$

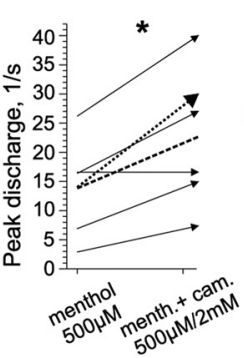

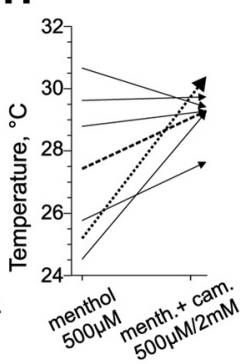

Figure 4. Camphor and menthol sensitize to cold via independent mechanisms. A-D, Camphor (2 mm)-induced sensitization to cooling is increased by subsequent coapplication of menthol (50 $\mu \mathrm{M}) . \boldsymbol{A}$, Original recording from a temperature-insensitive nociceptor (CM) showing instantaneous discharge rates in response to cooling after application of camphor ( 2 mM) and an equipotent dose of menthol $(50 \mu \mathrm{m})$. Lower trace, Time course of cold stimulus and threshold temperature of activation. $\boldsymbol{B}-\boldsymbol{D}$, Quantification of the synergistic effect of menthol on the camphor-induced cold sensitization: increase in response magnitude $(82.1 \pm 18.3-102.2 \pm 18.5 ; p=0.028$, Wilcoxon test; $\boldsymbol{B})$; increase in peak discharge (10.0 $\pm 2.4-16.6 \pm 4.0$ spikes/s, $p=0.028$, Wilcoxon test; $\boldsymbol{C}$; and rise in temperature threshold $\left(22.1 \pm 1.6^{\circ} \mathrm{C}-25.2^{\circ} \mathrm{C} \pm 1.3 ; p=0.046\right.$, Wilcoxon test; $\left.\boldsymbol{D}\right)$. Bold dotted lines: average of $n=10$, dotted arrow: representative sample shown in $\boldsymbol{A}$. $\boldsymbol{E}-\boldsymbol{H}$, Cold sensitization induced by a saturating dose of menthol is further increased by coapplication of camphor ( $2 \mathrm{~mm}$ ). $\boldsymbol{E}$, Original recording from a cold nociceptor showing instantaneous discharge rates in response to cooling after application of menthol $(500 \mu \mathrm{m})$ and camphor $(2 \mathrm{~mm})$. Lower trace, Time course of cold stimulus and threshold temperature of activation. $\boldsymbol{F}$ - $\boldsymbol{H}$, Quantification of the synergistic effect of camphor on the menthol-induced cold sensitization: increase in response magnitude $(71.8 \pm 19.6-92.1 \pm 24.1 ; p=0.1$, Wilcoxon test; $\boldsymbol{F})$ and peak discharge $(13.8 \pm$ 3.3-22.7 \pm 4.9 spikes $/ \mathrm{s}, p=0.04$, Wilcoxon test; $\boldsymbol{G})$, and rise in temperature threshold $\left(27.4 \pm 1.1^{\circ} \mathrm{C}-29.3 \pm 0.4^{\circ} \mathrm{C} ; \boldsymbol{p}=0.1\right.$, Wilcoxon test; $\left.\boldsymbol{H}\right)$. Bold dotted lines, Average of $n=6$; dotted arrow, representative sample shown in $\boldsymbol{E}$.

blocking effects. First, DRG cultures were screened for cold sensitivity, then the effect of camphor on the cold-activated calcium increase was evaluated. Cells were subsequently treated with menthol (Fig. $3 F$ ) and capsaicin (data not shown). Similar to the results in transiently transfected HEK293T cells, and as previously described, camphor had a mild and transient activating effect in a small number of neurons, which mainly affected cells that were also activated by $1 \mu \mathrm{M}$ capsaicin (Xu et al., 2005); since some of these neurons were also sensitive to menthol, this transient activation could also reflect a transient activation of TRPM8 (Fig. $3 F$, arrowhead). In menthol-sensitive cells, camphor showed a blocking effect on the cold-activated calcium influx. When two repeated cold stimuli were applied, and the second stimulus was applied in the presence of camphor, the blocking effect reached $53 \%(p=0.006$, $n=14$; Fig. $3 F$ ), but two repeated control cold stimuli showed a significant decline of the cold-activated calcium signal of $16 \%$ ( $p=$ $0.025 ; n=8$; Fig. $3 F$ ).

We assumed that the activating effect of camphor on TRPM8 was too weak and transient to explain the cold-sensitizing effects of camphor in the native nociceptors. In the presence of menthol and at cold temperatures, the blocking effect of camphor on TRPM8 was incomplete (Fig. 3C), and the amplitude of the remaining cold-activated TRPM8 current is large enough to allow for sufficient cold-activated generator potentials and propagated action potentials in the nociceptive terminals (Fig. 1). Therefore, we assumed that in nerve terminals camphor may act independently of TRPM8. We next tested whether coadministration of camphor and menthol results in a summation of cold-sensitizing effects.

\section{Menthol and camphor sensitize to cold via independent mechanisms}

C-fibers with previous cold sensitization by either camphor or menthol were tested for cross sensitivity to the respective other compound. First, we analyzed the combined effect of camphor and menthol at equipotent doses ( $2 \mathrm{~mm}$ and $50 \mu \mathrm{M}$; Fig. 2). Menthol coapplied with camphor significantly increased the camphor-induced cold sensitization in all three measures of sensitization, magnitude of cold response, peak discharge, and shift in threshold temperature ( $n=10$; Fig. $4 A-D)$. Nevertheless, the effect of the combination of the compounds appeared to be slightly less than additive. On one hand, this may be due to the desensitizing and partial blocking effect of camphor on TRPM8. Of more importance in terminal nerve endings could be the fact that strong sensitization also entails adaptation and/or desensitization, a phenomenon that we have previously described for capsaicin (St. Pierre et al., 2009). This would certainly result in reduced peak discharge and magnitude of responses. Therefore, in a second experiment we applied camphor $2 \mathrm{~mm}$ after application of menthol at a saturating dose of $500 \mu \mathrm{M}$, which induces adaptation and desensitization, as demonstrated in Figure 2, A and $C$. With this combination, we found similar potentiating effects of both compounds, which led to activation of all treated terminals at $30^{\circ} \mathrm{C}$ bath temperature $(n=6$; Fig. $4 E-H)$. These results suggest that the underlying mechanisms of action of both compounds are independent.

To find out more about the molecular mechanism of action of camphor in the fibers, we next used the patch-clamp technique in current-clamp mode on cold-sensitive cultured DRG neurons as 
A
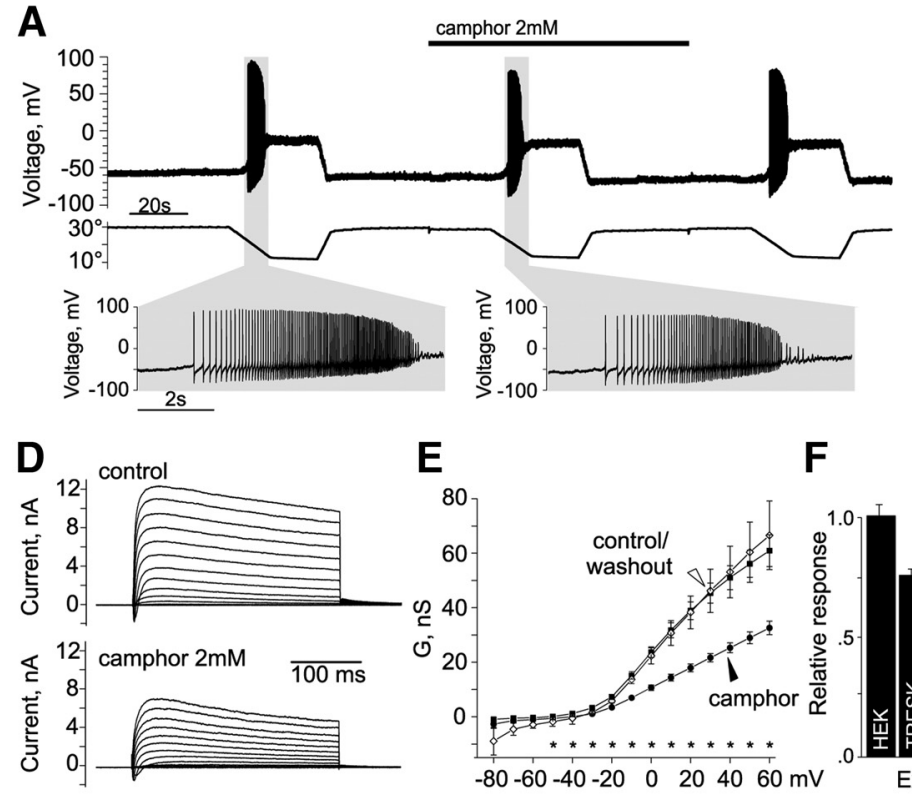

$E$

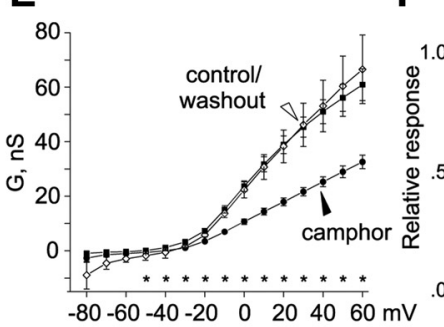

B

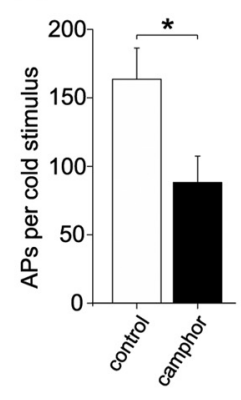

C

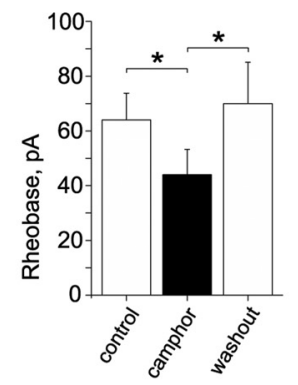

G

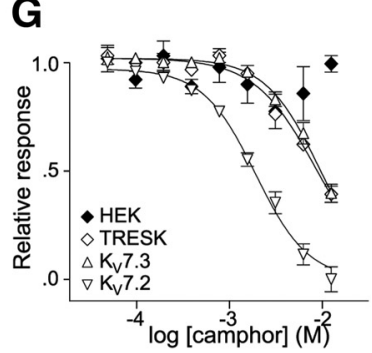

Figure 5. Camphor blocks potassium channels. $\boldsymbol{A}$, Top, Representative current-clamp recording from a cultured TRPM8-positive and cold-sensitive DRG neuron of a TRPM8EGFPf/+ mouse. Application of camphor did not induce action potential discharge, but caused partial reduction of the number of discharged action potentials during cooling (control, 116 spikes per cold stimulation; camphor, 77; wash, 106). The cold-activated voltage change and the temperature of activation were unchanged (22, 22.2, and $22.8^{\circ} \mathrm{C}$, respectively). Middle trace, Temperature time course. Bottom, Expanded first and second cold response. $\boldsymbol{B}$, Camphor reduced the cold response (action potentials discharge during the falling phase of the cold stimulus) in all TRPM8-expressing cells ( $n=5 ; p=$ 0.04 Wilcoxon test). C, Camphor reversibly decreased rheobase current, resulting in an increased excitability $(n=5)$. Current injections in $10 \mathrm{pA} \mathrm{steps} \mathrm{and} \mathrm{of} \mathrm{a} \mathrm{length} \mathrm{of} 1000 \mathrm{~ms}$ were applied ( $64 \pm$ $9.8,44 \pm 9.3$, and $70 \pm 15 \mathrm{pA}$, respectively; $n=5, p=0.04$, Wilcoxon test). $\boldsymbol{D}$, Potassium currents activated by depolarizing voltage pulses from $-80 \mathrm{to}+60 \mathrm{mV}$ from a holding potential of -60 $\mathrm{mV}$ in a cultured DRG neuron. Sodium currents were blocked with $700 \mathrm{~nm}$ TTX. $E, I-V$ relationship of potassium currents recorded in DRG neurons; the camphor-induced blocking effect could be washed out and reached $\sim 50 \%$ at positive voltages $\left(p<0.05, t\right.$ test). $F$, HEK293T cells transiently expressing the $K_{2} P$ channels TRESK, TRAAK, TREK1, and TREK2, and $K_{v} 7.2$ and $K_{v} 7.3$ were loaded with membrane potential dye, and the relative change in fluorescence was measured using a FLIPR Tetra plate reader and is shown as change relative to baseline. G, Stimulation with camphor caused a concentration-dependent change in fluorescence in HEK293T cells transiently expressing TRESK (open diamonds; $\mathrm{EC}_{50}=8.57 \mathrm{mM}$ ) or $\mathrm{K}_{\mathrm{v}} 7.3$ (open up-pointing triangles; $\mathrm{EC}_{50}=9.38 \mathrm{~mm}$ ). Cells expressing $\mathrm{K}_{\mathrm{v}} 7.2$ (open down-pointing triangles; $\mathrm{EC}_{50}=1.92 \mathrm{~mm}$ ) were most sensitive to camphor, while there was no effect in untransfected HEK cells (closed diamonds).

a model. Cold sensitivity is present only in a small fraction of DRG neurons in the mouse $(\sim 10 \%)$. Therefore, we identified cold-sensitive DRG neurons by using DRG preparations from heterozygous TRPM8 ${ }^{E G F P f /+}$ mice (Dhaka et al., 2008). In fluorescent small-sized neurons $(ø 16.6 \pm 1.64 \mu \mathrm{m})$, a cooling step from $30^{\circ} \mathrm{C}$ to $10^{\circ} \mathrm{C}$ repeatedly produced a large cold-activated voltage change of $39 \pm 2.7 \mathrm{mV}$ and triggered action potentials at a threshold temperature of $23.9 \pm 1.1^{\circ} \mathrm{C}$ (Fig. 5A). In these neurons, camphor $(2 \mathrm{~mm})$ reduced the number of action potential discharges in the falling phase of the cooling step by almost half (Fig. 5B). There was no change in the activation threshold of the neurons after camphor application $\left(23.8 \pm 1.1^{\circ} \mathrm{C}\right)$. This reversible reduction in action potential discharge may be due to a camphor-induced hyperpolarizing shift in sodium channel voltage dependence, which may result in reduced channel availability at depolarized potentials due to inactivation (Xu et al., 2005). The effect of camphor was also tested on five cold-insensitive neurons where camphor had no effect at any temperature applied. An effect of camphor on the excitability of DRG neurons was then investigated by measuring rheobase current. Therefore depolarizing current pulses of $1000 \mathrm{~ms}$ duration and increasing intensity were injected into the cells. Camphor induced a pronounced and reversible decrease in rheobase by $\sim 31 \%$ (Fig. $5 C$ ), which is in agreement with an increase in excitability. One likely explanation for this effect is reduced background potassium conductance. The effects of camphor on voltage-gated outward currents were monitored using $300 \mathrm{~ms}$ steps from -80 to $+60 \mathrm{mV}$ applied at 10 $\mathrm{mV}$ intervals from a holding potential of $-60 \mathrm{mV}$. Camphor inhibited potently and reversibly the outward current in DRGs by
$48-53 \%$ at positive potentials. This current is contributed by voltage-gated potassium channels of different types (Fig. $5 D, E$ ).

\section{$\mathrm{K}_{\mathrm{v}} 7.2$ potassium channels are sensitive to block by camphor and menthol}

To identify types of background and voltage-gated potassium channels blocked by camphor, we used a FLIPR Tetra-based screening assay where $\mathrm{K}_{2} \mathrm{P}$ potassium channels and $\mathrm{K}_{\mathrm{v}} 7$ subtypes were heterologously expressed in HEK293T cells and loaded with membrane potential dye. In this assay, the overall change in membrane potential is translated into a change in fluorescence. Of all $\mathrm{K}_{2} \mathrm{P}$ channels present in DRGs, we chose those that were modulated by temperatures, which includes TREK1, TREK2, and TRAAK (Kang et al., 2005; Alloui et al., 2006; Noël et al., 2009), and the most widely expressed $\mathrm{K}_{2} \mathrm{P}$ channel in mouse DRGs, TRESK (Kang and Kim, 2006; Dobler et al., 2007). $\mathrm{K}_{\mathrm{v}} 7.2$ and $\mathrm{K}_{\mathrm{v}} 7.3$ channels were included because they have profound influence on nociceptor excitability. Subtypes coassemble to form the $\mathrm{M}$-current, which is present in nociceptors and has a threshold of activation near resting membrane potential $(-60 \mathrm{mV}$ ) (Schroeder et al., 1998; Wang et al., 1998; Linley et al., 2008; Passmore et al., 2012). In this assay, $\mathrm{K}_{\mathrm{v}} 7.2$ was most sensitive to camphor with an $\mathrm{EC}_{50}$ of $1.9 \mathrm{~mm}$; TRESK and $\mathrm{K}_{\mathrm{v}} 7.3$ were much less sensitive to block by camphor $\left(\mathrm{EC}_{50}\right.$ of 8.6 and $9.4 \mathrm{~mm}$, respectively; Fig. $5 F, G)$. To validate the membrane potential assay, we next tested the effect of camphor on potassium channels in patch-clamp experiments. Indeed, heterologously expressed $\mathrm{K}_{\mathrm{v}} 7.2$ proved to be most sensitive to camphor, and half-maximal block was attained with $500 \mu \mathrm{M}$ camphor. Heteromultimers were less sensi- 
A

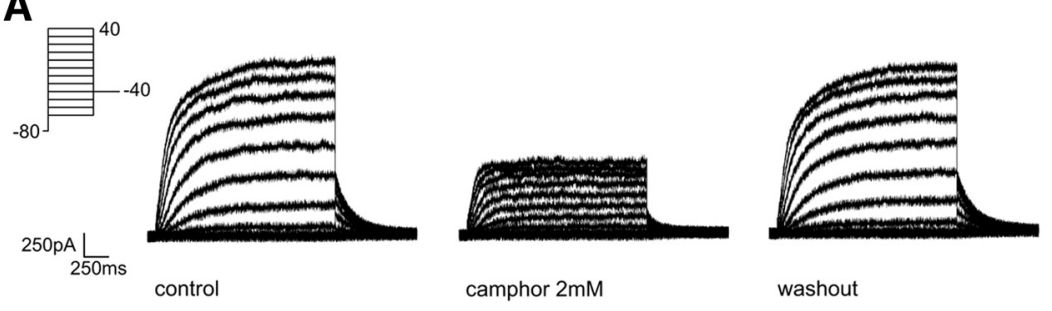

B
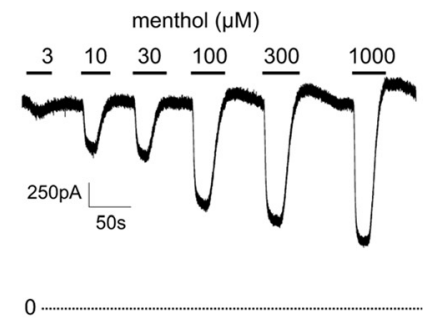

D

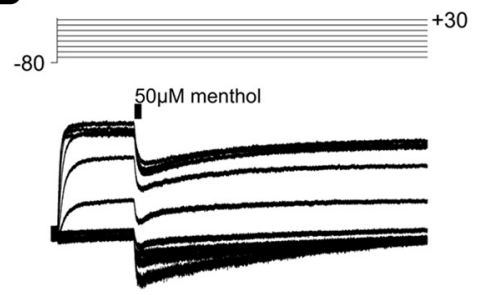

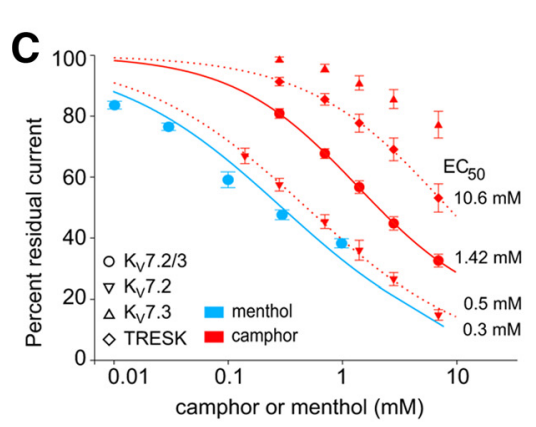

E

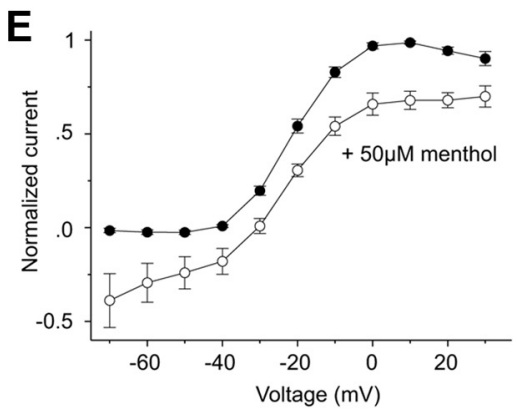

Figure 6. Camphor and menthol inhibit $\mathrm{K}_{\mathrm{v}} 7.2 / \mathrm{K}_{\mathrm{v}} 7.3$ channels. $A$, Sample trace of $\mathrm{K}_{\mathrm{v}} 7.2$ in response to the indicated voltage step protocol showing block by camphor and washout. B, Outward currents mediated by $K_{v} 7.2 / K_{V} 7.3$ channels of HEK293T cells were dose dependently and reversibly inhibited by increasing concentrations of menthol (3-1000 $\mu \mathrm{m})$. Holding potential, $0 \mathrm{mV}$. C, Blocking effect of camphor (red) on different $\mathrm{K}^{+}$channels depicted as fitted average. $\mathrm{K}_{\mathrm{V}} 7.2 / 3$ (red circles): $\mathrm{IC}_{50}=1.42 \pm 0.20 \mathrm{~mm}$; minimum, $15.18 \pm 3.77 \%$; Hill coefficient, $0.88 \pm 0.07(n=9) . \mathrm{K}_{\mathrm{V}} 7.2$ (down-pointing triangles): $\mathrm{IC}_{50}=0.53 \pm 0.11 \mathrm{~mm}$; minimum, $2.76 \pm 1.56 \%$; Hill coefficient, $0.70 \pm 0.02(n=12) . K_{\mathrm{v}} 7.3$ (up-pointing triangles) was least affected by camphor $(n=$ 4). TRESK (rhombs): $I C_{50}=10.62 \pm 3.62 \mathrm{~mm}$; minimum, $11.35 \pm 4.65 \%$; Hill coefficient, $0.79 \pm 0.07(n=9)$. Relative inhibition of $\mathrm{K}_{\mathrm{v}} 7.2 / \mathrm{K}_{\mathrm{v}} 7.3$ outward current by menthol (blue circles) was plotted as a function of menthol concentration. A logistic equation was fitted to the dose-response data, yielding an $\mathrm{EC}_{50}$ of $298 \mu \mathrm{m}$ ( $n \geq 10$ for each data point). D, Menthol (50 $\mu \mathrm{m}$ ) had synergistic effects on TRPM8 and $K_{v} 7.2 / K_{v} 7.3$ channels cotransfected in HEK293T cells. At each command potential, a brief pulse of menthol $(50 \mu \mathrm{m})$ was spritzed onto the recorded cells. Menthol-induced inward currents resulted predominantly from TRPM8 activation and $K_{v} 7.2 / K_{v} 7.3$ inhibition at hyperpolarized and depolarized potentials, respectively. $\boldsymbol{E}, I-V$ relationships were calculated from experiments of $\boldsymbol{D}$ immediately before menthol application (black circles) and during peak menthol effect (open circles). Currents were normalized to their maximal amplitude before spritzing menthol $(n=9)$. All error bars indicate SEM.

tive and required $1.42 \mathrm{~mm}$ camphor for half-maximal block. The $\mathrm{K}_{2} \mathrm{P}$ channel most sensitive to block by camphor was TRESK, requiring $10.6 \mathrm{mM}$ camphor for half-maximal block (Fig. 6A, C). TREK1, TREK2, and TRAAK were insensitive to lower concentrations of camphor. Overall, the membrane potential assay yielded approximately comparable results, and is therefore a convenient and fast method for target screening on potassium channels.

We next asked whether menthol exerts a similar effect on $\mathrm{K}_{\mathrm{V}} 7$ channels. HEK293T cells were voltage-clamped to $0 \mathrm{mV}$ at room temperature to activate outward currents generated by transiently expressed heteromeric $\mathrm{K}_{\mathrm{V}} 7.2 / 7.3$ channels. When applied under these conditions, increasing concentrations of menthol $(3-1000 \mu \mathrm{M})$ produced apparent inward current responses of increasing amplitudes that resulted from the dose-dependent inhibition of $\mathrm{K}_{\mathrm{V}} 7.2 / 7.3$ channels (Fig. $6 B$ ). From the dose-response relationship depicted in Figure $6 C$, we calculated a half-maximal block of the outward current at $289 \mu \mathrm{M}$, thus yielding an $\mathrm{EC}_{50}$ value for menthol that was considerably lower than that for camphor.

To investigate a synergistic action of menthol on cold-sensing effectors, we cotransfected $\mathrm{K}_{\mathrm{V}} 7.2 / \mathrm{K}_{\mathrm{V}} 7.3$ channels with TRPM8. Starting from a holding potential of $-80 \mathrm{mV}$, HEK cells were depolarized stepwise in $10 \mathrm{mV}$ increments. At each command potential, a $0.5 \mathrm{~s}$ pulse of menthol $(50 \mu \mathrm{M})$ was spritzed onto the cell. At hyperpolarized potentials, activation by menthol of TRPM8 gave rise to a transient inward current that decreased as the command potentials became less negative, thereby reducing the driving force. As command potentials were made more depolarized, the effect of menthol grew in size, now reflecting its blocking action on $\mathrm{K}_{\mathrm{V}}$ 7.2/7.3 channels, as shown above (Fig. $6 D)$. These data demonstrate that, with its simultaneous effect on TRPM8 and $\mathrm{K}_{\mathrm{V}} 7.2 / 7.3$ channels, menthol is capable of providing increased transducing inward current over the entire voltage range (Fig. 6E). To investigate whether block of these $\mathrm{K}_{\mathrm{V}}$ potassium channels is relevant for the cold-sensitizing effect of camphor and menthol, we next applied XE991, a specific blocker of $\mathrm{K}_{\mathrm{V}} 7$ channels, to receptive fields of CMC fibers in skin-nerve preparations.

\section{Like camphor, M-current blocker XE991 amplifies cold transduction}

The effect of XE991 was recently analyzed in the rat skin-nerve preparation, but only with respect to modulation of heat sensing. In this study, application of XE991 sensitized A-fibers to heat and induced ongoing activity at bath temperature, while no effect on C-fibers was found (Passmore et al., 2012). The $\mathrm{EC}_{50}$ for XE991 lies in the low-micromolar range, and we used $10 \mu \mathrm{M}$, corresponding to the $\mathrm{EC}_{80}$ for heterologously expressed $\mathrm{K}_{\mathrm{V}} 7.2$ and $\mathrm{K}_{\mathrm{V}} 7.3$ (Wang et al., 1998) or the $\mathrm{EC}_{60}$ for acutely dissociated DRGs (Rose et al., 2011). Subsequently and in the same fibers, we also applied $100 \mu \mathrm{M}$, because the $\mathrm{IC}_{50}$ for $\mathrm{K}_{\mathrm{V}} 7.5$ subtypes, which potentially dominate in C-fibers according to a recent report (King and Scherer, 2012), is much higher with 60-70 $\mu \mathrm{M}$ (Schroeder et al., 2000). After washout of XE991, each fiber was tested with menthol or camphor for cross-sensitization to cold. We specifically searched for mechanosensitive C-fibers with cold-sensitivity and found that $10 \mu \mathrm{M}$ XE991 sensitized 7 of 10 CMC fibers to cold. All of the sensitized fibers increased their cold response further upon treatment with camphor or menthol (Fig. $7 A, B$ ). The sensitization to cold by XE991 occurred only in cold nociceptors (CMC fibers), not in multimodal nociceptors (CMCH: $n=2)$ or polymodal nociceptors (CMH: $n=3$ ), but also in none of the thermoinsensitive units (CM: $n=3$ ). This was in accordance with the sub- 
A CMC-unit, $0.7 \mathrm{~m} / \mathrm{s}, 1 \mathrm{mN}$

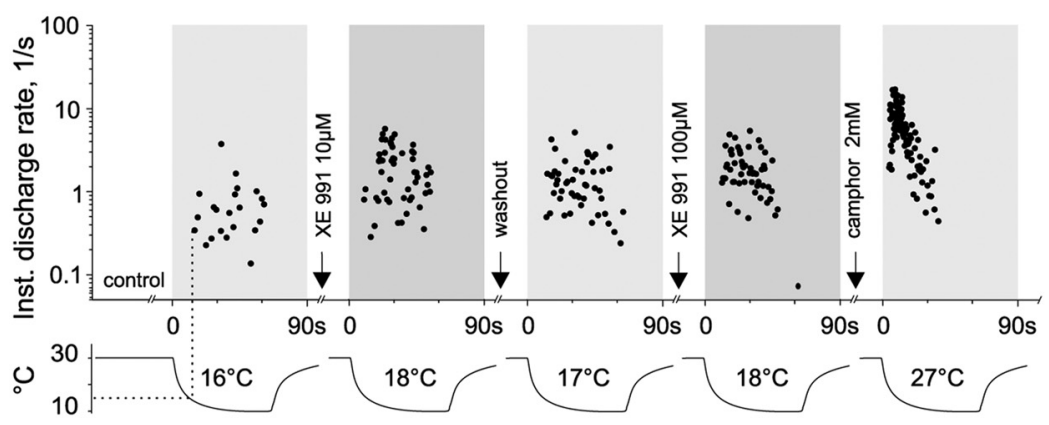

D CMC-unit, $0.7 \mathrm{~m} / \mathrm{s}, 4 \mathrm{mN}$

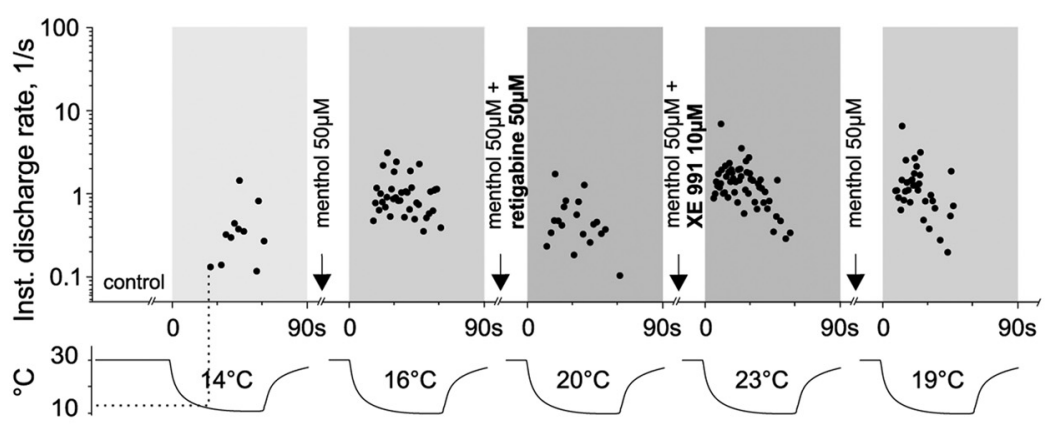

B

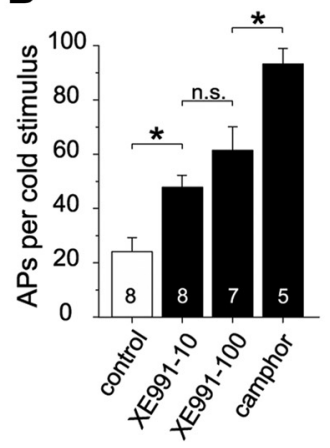

E

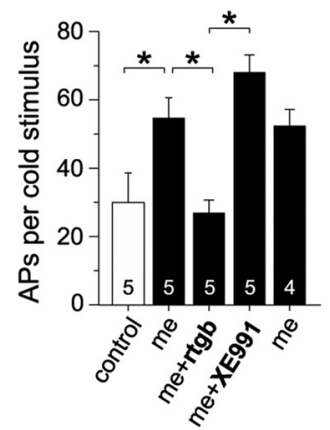

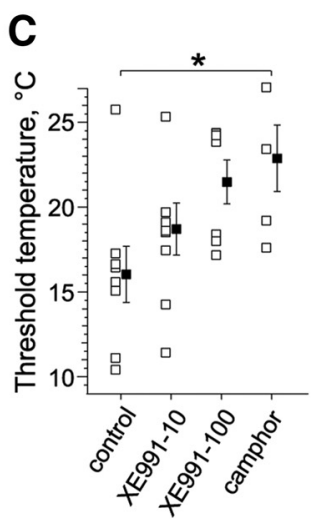

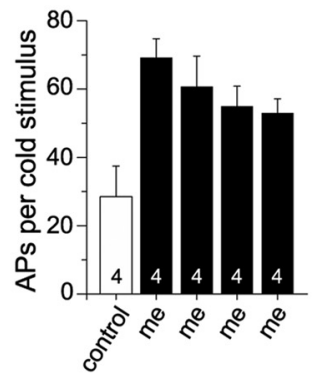

Figure 7. $\mathrm{K}_{\mathrm{v}} 7$ channel modulators XE991 and retigabine have opposite effects on cold sensing in CMC fibers. $\boldsymbol{A}$, Original recording showing instantaneous discharge rates in response to cooling and XE991 application. XE991 $10 \mu \mathrm{m}$ produced sensitization to cold in camphor-sensitive CMC fibers. Interstimulus interval and drug wash-in was 4 min. Lower trace, Time course of cold stimulus and temperature thresholds of activation. $\boldsymbol{B}$, Cold-sensitizing effect of subsequently applied 10 and $100 \mu \mathrm{m}$ XE991 shown as an increase in magnitude of the cold response. XE991 $10 \mu \mathrm{m}$ increased the cold response by 2.7-fold, and $100 \mu \mathrm{m}$ by 2.9-fold ( $n=7, p=0.06, t$ test). Camphor, applied after washout of XE991, increased the cold response by 4.2 -fold over baseline (mean of $n=5$ CMC fibers), which was significantly more than XE991 (vs $10 \mu \mathrm{M}, p=0.002$; vs $100 \mu \mathrm{M}, p=0.03, t$ test). Block of $\mathrm{K}_{\mathrm{v}} 7$-channels by XE991 may explain $\sim 64-69 \%$ of the cold sensitization of camphor.

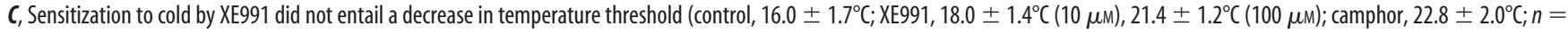
$8 / 8 / 7 / 5 ;{ }^{*} p=0.02, t$ test). D, Original recording showing instantaneous discharge rates in response to cooling and combined application of menthol ( $50 \mu \mathrm{m}$ ) and retigabine or XE991. Interstimulus interval and drug wash-in was 4 min. Lower trace, Time course of cold stimulus and temperature thresholds of activation. $E$, Addition of $50 \mu m$ retigabine reversed menthol-induced cold sensitization in CMC fibers (reduction by 51\%), while the addition of XE991 restored and further boosted the menthol effect (increase by $33 \% ; n=4-5 ; p<0.007, t$ test); in contrast, repeated cold stimulation in the presence of menthol alone showed a progressive decline of the menthol-sensitized cold response by $15 \%, 21 \%$, and $23 \%$, respectively $(n=4 ; p>0.05, t$ test). Error bars represent $\mathrm{SEM}$.

populations of fibers sensitized to cold by camphor and menthol (compare Figs. $1 B, 2 B$, Table 2). The cold sensitization was independent of any direct effect of XE991 on TRPM8, because addition of XE991 on heterologously expressed TRPM8 at concentrations up to $100 \mu \mathrm{M}$ neither activated TRPM8 nor inhibited responses evoked by addition of menthol ( $50 \mu \mathrm{M}$; using a FLIPR Tetra fluorescent $\mathrm{Ca}^{2+}$ assay; data not shown).

There were some differences between the effects of XE991 and camphor: XE991 had no significant sensitizing effect on the activation threshold (Fig. 7C) and on the peak discharge of the cold nociceptors (not illustrated). XE991 shifted the threshold by $2.0 \pm 1.8^{\circ} \mathrm{C}$ (mean $\pm \mathrm{SEM} ; n=8 \mathrm{CMC}$ fibers, $p=0.2$, Wilcoxon test; camphor: $7.4 \pm 1.3^{\circ} \mathrm{C} ; n=15 \mathrm{CMC}$ fibers) and changed the peak discharge by $1.3 \pm 1.4$-fold $(n=$ $8, p=0.4$, Wilcoxon test; camphor: $5.2 \pm 0.6$-fold). However, in accordance with a suprathreshold effect on cold transduction, XE991 significantly increased the mean discharge rate per second during the cold response from $0.7 \pm 0.4$ to $1.5 \pm$ 0.9 spikes/s $(n=8, p=0.02$, Wilcoxon test; camphor: $1.0 \pm$ $0.1-3.6 \pm 0.3 ; n=15$ CMC fibers, $p=0.005$; not illustrated). On average, the saturating $100 \mu \mathrm{M}$ concentration of XE991 was almost equally effective as the $10 \mu \mathrm{M}$ concentration $\left(\mathrm{EC}_{80}\right.$ concentration at $\mathrm{K}_{\mathrm{V}} 7.2$ and 7.3), and produced a total increase in the magnitude of the cold response of $2.9 \pm 0.4$-fold (XE991 $10 \mu \mathrm{M}$ : $2.7 \pm 0.4$-fold; Fig. $7 B$ ). However, on an individual basis, four of seven fibers showed further increased sensitization upon exposure to $100 \mu \mathrm{M}$ XE991: the magnitude of their cold response increased by an additional 30\% (compared with $10 \mu \mathrm{M}$ XE991), which possibly indicates that in particular fibers the recruitment of other $\mathrm{K}_{\mathrm{V}} 7$ channel subtypes, like $\mathrm{K}_{\mathrm{V}} 7.5$, occurs (Wang et al., 1998; King and Scherer, 2012). Together, XE991 was less effective than camphor, which amplified the cold response by $4.2 \pm 0.5$-fold (Fig. $7 B$ ). Nevertheless, from these results, block of M-current can explain more than half of the cold-sensitizing effect of camphor at 2 $\mathrm{mm}$ in mechanosensitive C-fibers $(\sim 64-69 \%)$.

To estimate the extent of M-channel block contributing to menthol-activated cold responses, we used the potent M-channel opener retigabine in combination with menthol. Retigabine was previously shown to be effective in rescuing M-channel function from block (Linley et al., 2012), and thus might overcome menthol-induced inhibition of the M-current (Fig. 6B-E). We found that the sensitizing effect of menthol could be entirely reversed by the addition of retigabine at supramaximal concentration $(50 \mu \mathrm{M})$, and that this effect was immediately reversed by superfusion with XE991 $10 \mu \mathrm{M}$ (Fig. 7 D,E). Like XE991, retigabine neither activated TRPM8 nor inhibited responses evoked by the addition of menthol ( $50 \mu \mathrm{M}$; using a FLIPR Tetra fluorescent $\mathrm{Ca}^{2+}$ assay; data not shown). 

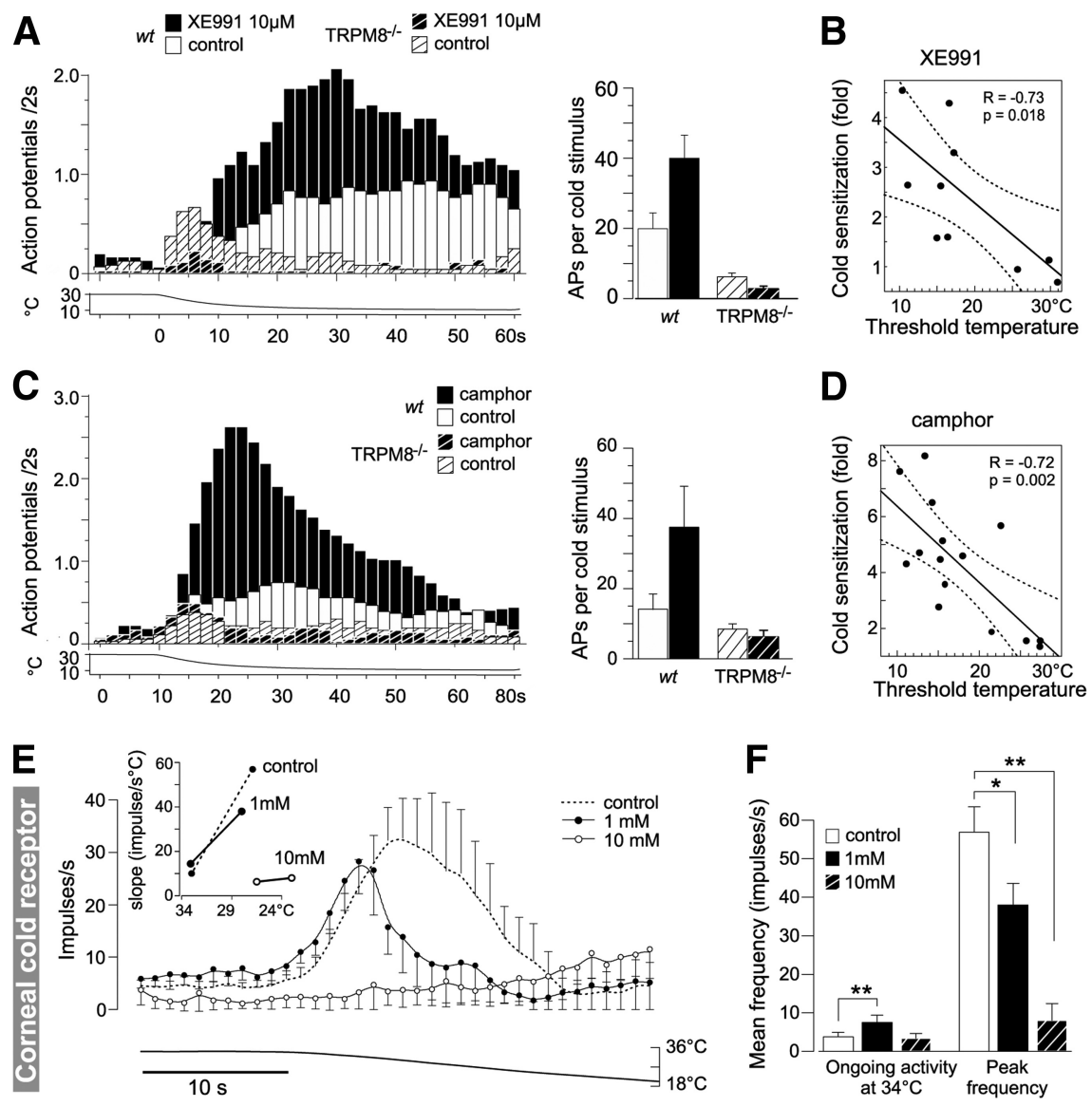

Figure 8. Cold sensitization by XE991 and camphor requires TRPM8. A, Averaged histogram of cold sensitization by XE991 10 $\mu \mathrm{m}$ in bins of $2 \mathrm{~s}$ in wild type (wt; black bars, $n=10 \mathrm{CMCH}$ ) and TRPM8 ${ }^{-1-}$ (white bars, $n=8$ ). XE991 sensitization to cold was present in fibers from C57BL/6 $(n=8)$ and TRPM8 ${ }^{+/+}(n=2)$ but not in TRPM8 ${ }^{-/-}$fibers. Lower trace, Time course of cold stimulus. Right, Bar chart summarizing XE991 sensitization to cold per 60 s cold stimulus in both genotypes (wt: 19.9 $\pm 4.5-40 \pm$ $6.5 ; p=0.02, t$ test; TRPM8 ${ }^{-1-}: 6.2 \pm 1.1-2.7 \pm 0.8$ ). $B$, Correlation between activation threshold temperature of cold nociceptors (CMC) and cold sensitization by XE991 plotted as the fold increase in response magnitude (action potentials per cold stimulus of $60 \mathrm{~s}$ ); dotted line, 0.95 confidence interval. C, Averaged histogram of cold sensitization by camphor in bins of $2 \mathrm{~s}$ recorded from TRPM8 ${ }^{+/+}$(black bars, $n=18 \mathrm{CMCH}_{\text {fibers}}$ ) and TRPM8 ${ }^{-1-}$ (white bars, $n=10$ ). The sensitization to cold of camphor was reproduced in wt but not in TRPM8-deficient fibers. Lower trace, Time course of cold stimulus. Right, Bar chart summarizing camphor sensitization to cold per 60 s cold stimulus in both genotypes (wt: $14.2 \pm 4.3-37.6 \pm 12.6 ; p=0.08, t$ test; TRPM8 $^{-1-}: 7.8 \pm 1.6-6.1 \pm 1.7$. D. Correlation between activation threshold temperature of cold nociceptors and cold sensitization by camphor plotted as the fold increase in response magnitude (action potentials per cold stimulus of $60 \mathrm{~s}$ ) for $15 \mathrm{CMC}$ fibers. $\boldsymbol{E}$, Mean firing frequency of corneal cold thermoreceptors from C57BL/6 mice in control solution (dotted line), in camphor 1 $\mathrm{mm}$ (black circles) and $10 \mathrm{~mm}$ (white circles). The figure displays the activity before (10 s) and during a dynamic cooling ramp from 34 to $20^{\circ} \mathrm{C}$ illustrated in the bottom trace. Inset, Mean slope (see Materials and Methods) of the change of frequency between the cooling threshold and the peak frequency versus temperature during dynamic cooling ramps (dotted line): $9.1 \pm 1.7$ versus camphor $1 \mathrm{~mm}$ (black circles) $8.8 \pm 3.1$ impulses $/ \mathrm{s} /{ }^{\circ} \mathrm{C}$ and $10 \mathrm{~mm}$ (white circles) $0.5 \pm 0.3$ impulses $/ \mathrm{s} /{ }^{\circ} \mathrm{C} ; n=7$; paired $t$ test: $p=$ 0.003). Errors bars represent the SEM. $\boldsymbol{F}$, Mean activity, shown as impulses per second at $34^{\circ} \mathrm{C}$, is increased by the application of camphor $1 \mathrm{~mm}$ for $3.4 \mathrm{~min}$, while the maximum response during a dynamic cooling ramp is attenuated or blocked after application of camphor 1 or $10 \mathrm{~mm}$, respectively. Ongoing activity: $3.7 \pm 1.2 \mathrm{impulses} / \mathrm{s}$ (control) vs $7.5 \pm 1.9 \mathrm{impulses} / \mathrm{s}$ at $1 \mathrm{~mm}(n=7)$ and $3.4 \pm 1.2 \mathrm{impulses} / \mathrm{s}$ at $10 \mathrm{~mm}(n=10) ;$ paired $t$ test, $p=0.003$ and $p=0.5$, respectively; peak frequency: $56.9 \pm 6.7 \mathrm{impulses} / \mathrm{s}$ (control) versus $38.0 \pm 5.6 \mathrm{impulses} / \mathrm{s}$ at $1 \mathrm{~mm}$ and $8 \pm 4.4 \mathrm{impulses} / \mathrm{s}$ at $10 \mathrm{~mm} ; n=7$; paired $t$ test, $p=0.01$ and $p=0.004$, respectively. Errors bars represent the SEM.

\section{Block of M-current is not sufficient to initiate cold transduction}

So far, we have demonstrated that camphor, menthol, and the specific M-current blocker XE991 can produce cold sensitization, but only in CMC fibers, the fiber type that is absent in TRPM8deficient mice, and in some menthol-sensitive CM fibers. This observation raises the question of whether the block of potassium channels, like the M-current, is sufficient to induce cold transduction in terminal nerve endings or whether the depolarization only amplifies a generator potential provided by cold-activated inward current. To answer this question, we analyzed cold sensitization by XE991 and camphor in TRPM8-deficient mice. In a large sample of TRPM8 ${ }^{-1-}$ fibers, camphor and XE991 failed to induce cold sensitization $(n=32$ and $n=22$, respectively). In contrast, in age- and sex-matched littermate control mice, the cold sensitization of camphor could be reproducibly induced in the same fiber subtypes as in $\mathrm{C} 57 \mathrm{BL} / 6$ mice ( $n=32$; Fig. 8 A, $C$; Table 2); similarly, the cold-sensitizing effect of XE991 was reproduced in two CMC fibers from TRPM $8^{+/+}$mice. In conclusion, in the case of camphor and XE991, block of potassium channels leads to a reduction of the voltage change across the membrane, which is insufficient to reach the action potential threshold. Nevertheless, it results in a considerable augmentation of the transduction current by TRPM8. This yields discharge of more action potentials and higher firing rates during cooling. Thus, XE991-in contrast to camphor-amplifies cold transduction mainly when cold transduction is activated and the threshold is exceeded, while camphor also exhibited a significant effect on the threshold and shifted it by $>5^{\circ} \mathrm{C}$ to lower temperatures. This additional effect of camphor is similar to menthol $\left(\sim 9^{\circ} \mathrm{C}\right.$ shift $)$ and may be mediated by TRPM8 agonism in combination with inhibitory effects on other potassium channel subtypes.

\section{Equilibrium of $\mathrm{K}_{\mathrm{v}} 7$ channels and TRPM8 receptors in somatic cold nociceptors}

Previously, potassium channels of the $\mathrm{K}_{\mathrm{V}} 1$ family were identified to play a crucial role in the setting of the activation threshold of cultured cold-sensitive trigeminal neurons, and their expression was reported to form equilibrium with TRPM8 expression. This equilibrium is functionally conferred by inverse correlations between the threshold temperature of activation of the cold-sensitive neurons and $\mathrm{K}_{\mathrm{V}} 1$ current density (negative correlation) and TRPM8 current density (positive correlation; $\mathrm{Ma}$ drid et al., 2009). We next investigated whether in somatic cold nociceptors a similar inverse relationship exists for $\mathrm{K}_{\mathrm{V}} 7$ channel availability and temperature threshold of activation of the cold nociceptors. In extracellular skin-nerve recordings, we have no means to determine $\mathrm{K}_{\mathrm{V}} 7$ channel density as current density, but it may be indirectly derived from the magnitude of the cold-sensitizing effect achieved by inhibitors XE991 and camphor. Figure $8, B$ and $D$, illustrates that, similar to the published findings in the trigeminal system, the fibers with the highest temperature 
threshold showed the largest amplification of their cold response on camphor or XE991 application, while fibers with threshold close to resting temperature $\left(30^{\circ} \mathrm{C}\right)$ showed little increase in their cold response after treatment with either compound.

In contrast to the cold nociceptors in the skin, low-threshold corneal cold thermoreceptors show an extremely high sensitivity to small temperature decreases (Parra et al., 2010). TRPM8 is essential, and a lack of $\mathrm{K}_{\mathrm{V}} 1$ potassium channels is a characteristic feature of these particular receptors and is evidenced by a lack of effect of potassium channel blockers like 4-AP $(100 \mu \mathrm{M})$ on the cooling threshold (Madrid et al., 2009; Parra et al., 2010). In these fibers, superfusion of camphor ( $1 \mathrm{~mm}$ ) led to a transient activation at bath temperature and a decrease in the dynamic cooling response, much like the effect of camphor on heterologously expressed TRPM8 (Fig. 8E,F). In contrast, higher concentrations $(10 \mathrm{~mm})$ fully blocked the cold response. These effects may be explained by transient agonism, partial block, and desensitization of TRPM8.

\section{Discussion}

Specialized thermosensitive nerve endings in the skin are endowed with a large variety of ion channels to detect a broad range of cold temperatures. In this study, we identify for the first time a functional synergism between $\mathrm{K}_{\mathrm{V}} 7$ potassium channels forming the M-current and TRPM8-activated cold sensing in cutaneous cold nociceptor nerve endings. In detail, we show that camphor, a natural compound with promiscuous effects on various TRPs, mediates its psychophysically measurable effect of sensitization to cooling by modulating TRPM8-dependent cold transduction in nociceptors via block of $\mathrm{K}_{\mathrm{V}} 7$ channels. In addition, menthol proved to be an even more potent M-channel blocker. In accordance with these findings, inhibition of $\mathrm{K}_{\mathrm{V}} 7$ by the specific M-current blocker XE991 resulted in sensitization of TRPM8dependent cold transduction, while the M-channel enhancer retigabine attenuated cold transduction. Neither camphor nor XE991 modulates cold transduction in TRPM8-deficient fiber types or fibers from TRPM8-deficient mice. The differential effects of camphor in cultured DRG cell bodies (reduction of cold-activated responses) and terminal nerve endings (potent sensitization to cold) suggest important differences between both models.

In nerve terminals, as expected, menthol dramatically increased the cold-induced action potential discharge and induced a shift in temperature activation threshold by almost $9^{\circ} \mathrm{C}$ at 50 $\mu \mathrm{M}$, but induced firing at $30^{\circ} \mathrm{C}$ only at very high concentration. Thereby the effects of menthol in the terminals directly reflect observations from current measurements of heterologously expressed TRPM8: depending on the expression level, coldactivated currents are of small amplitude, but can undergo a large increase following chemical sensitization (Peier et al., 2002). Camphor induced a similar sensitization to cold in an equally large proportion of cutaneous terminals as menthol, affecting the same subpopulation of mechanosensitive C-fibers. In contrast, its effects on heterologously expressed rat and human TRPM8 were notably different from menthol and rather complex: camphor induced a brief activation, but was a far weaker agonist than menthol, and activation was regularly followed by desensitization. These actions on recombinant TRPM8 contrast the profound and menthol-like cold-sensitizing effects of camphor in cold nociceptors. Apart from that, camphor seemed to partly inhibit agonist-activated TRPM8: it blocked the mentholactivated current through the recombinant channel, but had much less blocking influence on the cold-induced current of recombinant TRPM8 or the cold-activated $\mathrm{Ca}^{2+}$ increase and action potential firing of TRPM8-expressing cultured DRGs. In fact, a weak blocking effect of camphor on recombinant TRPM8 was previously mentioned (Vogt-Eisele et al., 2007), and the effects of camphor on TRPV1 are similar: rapid activation is followed by profound desensitization (Xu et al., 2005; Marsakova et al., 2012). In fact, in the nerve terminals the potent coldsensitizing action of camphor seemed to require more than weak TRPM8 agonism, because coapplication of equipotent concentrations of camphor and menthol produced additive effects, and even cold sensitization by a saturating concentration of menthol was further enhanced by camphor.

\section{The most obvious effect of camphor in cultured DRGs was a block of potassium outward currents}

Potassium channel block is already a recognized principle to explain part of the cold-induced increase in membrane resistance, which partly depends on leak channels of the $\mathrm{K}_{2} \mathrm{P}$ channel family. The most widely expressed $\mathrm{K}_{2} \mathrm{P}$ channel in murine DRG neurons, TRESK (Kang and Kim, 2006; Dobler et al., 2007) was only weakly blocked by camphor as measured in our membrane potential assay and confirmed in patch-clamp experiments (block of $\sim 20 \%$ at $2 \mathrm{~mm}$ ). Other $\mathrm{K}_{2} \mathrm{P}$ channels, like TREK1, TREK2, and TRAAK, undergo cooling-dependent closure, but were not affected by camphor. Nevertheless, the small effect on TRESK may contribute to the cold sensitization and synergize with the genuine effects of cooling.

In nociceptive neurons, $\mathrm{K}_{\mathrm{V}} 7$ channel subtypes form the noninactivating $\mathrm{M}$-current, which affects the neuronal resting membrane potential. Inhibition of the M-current is pronociceptive and occurs under inflammatory conditions conveyed, for example, by mediators coupling to phospholipase C (Linley et al., 2008, 2012). Modulation of M-current directly affects membrane excitability in all types of neurons, which is documented by inherited loss-of-function mutations within M-channel genes $\left(\mathrm{K}_{\mathrm{V}} 7.1-\mathrm{K}_{\mathrm{V}} 7.5\right)$. In case of $\mathrm{K}_{\mathrm{V}} 7.2$, this result in peripheral nerve hyperexcitability states and benign familial neonatal seizures (Miceli et al., 2012). Indeed, excess topical exposure or accidental ingestion of camphor in children can result in tonic-clonic seizures (Love et al., 2004).

\section{De novo cold sensitivity in cutaneous nociceptors may be a sign of high M-channel activity}

A remarkable finding of the present study was that menthol as well as camphor induced de novo cold responsiveness in a large proportion (45-60\%) of mechanosensitive C-fibers. These units have functional cold transducers, but the cold-activated generator potential is too small to reach the threshold for action potential generation. When cooling is combined with menthol or camphor, the generator potential increases and cold-sensitivity becomes apparent. De novo cold sensitivity may be a sign for a particularly high M-channel activity, which in case of menthol (or camphor) application is attenuated and contributes to the sensitized cold response. This coherence is also in line with our finding that application of the $\mathrm{M}$-channel enhancer retigabine dramatically reduced menthol-sensitized cold responses in CMC fibers. These particular types of nociceptors may undergo recruitment under pathophysiological conditions (e.g., in response to contact with an endogenous agonist or sensitizer), like bradykinin is one in recruiting heat responsiveness (Reeh and Pethö, 2000) and causing M-channel block (Linley et al., 2012). 
Remarkably, from all cold-sensitive units treated with menthol, only one-third were sensitized to cold. The remaining cold-sensitive units either rely on another cold-transducing mechanism enabling the inward current for the generator potential or are TRPM8 positive, but suffer desensitization (Cliff and Green, 1996; Rohács et al., 2005). In this respect, we also observed mixed sensitizing and desensitizing effects with the TRPV1 agonist capsaicin when applied to receptive fields (St. Pierre et al., 2009).

\section{Functional synergism between $\mathrm{K}_{\mathrm{v}} 7$ channels and TRPM8- dependent cold transduction}

The finding that XE991, a selective blocker of $\mathrm{K}_{\mathrm{V}} 7$ channels, induced potent cold sensitization in the same camphor- and menthol-sensitive TRPM8-expressing fibers, but not in other types of fibers, suggests that the contribution of $\mathrm{K}_{\mathrm{V}} 7$ channels to enhanced cold transduction is specific to TRPM8-expressing pathways.

In contrast to camphor, XE991 was less effective but still more than doubled cold responses when used at the $\mathrm{EC}_{80}$. The coldsensitizing effect of camphor was quantified using $2 \mathrm{~mm}$, which represents the $\mathrm{EC}_{50}$ in $\mathrm{K}_{\mathrm{V}} 7$ heteromultimers $\left(\mathrm{K}_{\mathrm{V}} 7.2 / \mathrm{K}_{\mathrm{V}} 7.3\right)$, although $\mathrm{K}_{\mathrm{V}} 7.2$ was determined to be more sensitive with an $\mathrm{EC}_{50}$ of $0.5 \mathrm{~mm}$. The blocking effect of menthol on $\mathrm{K}_{\mathrm{V}} 7.2$ was larger, with an $\mathrm{EC}_{50}$ of $0.29 \mathrm{~mm}$. Referring to the increase in the magnitude of the cold response induced by XE991, block of $\mathrm{K}_{\mathrm{V}} 7$ channels may explain approximately two-third of the cold-sensitizing effects of camphor and certainly some of the cold-sensitizing effects of menthol in terminal nerve endings. The remaining cold-sensitizing effect of camphor should be mediated by other ion channels, which may include the $\mathrm{K}_{2} \mathrm{P}$ channel TRESK.

In general, block of the $\mathrm{M}$-current is induced by an increase in intracellular $\mathrm{Ca}^{2+}$ and depletion of membrane phosphatidylinositol 4,5-bisphosphate $\left(\mathrm{PIP}_{2}\right)$, which can occur independent of each other (Gamper et al., 2005; Linley et al., 2008). In cold nociceptors, $\mathrm{Ca}^{2+}$ is provided directly through cold-activated TRPM8, and usually, sustained opening of TRPM8 results in $\mathrm{PIP}_{2}$ depletion and decreased activity or adaptation of the cold sensors (Rohács et al., 2005; Daniels et al., 2009; Yudin et al., 2011). This is also applicable to the peripheral endings, where the highest concentration of menthol induced strongest adaptation. Inhibition of M-current could thus be a direct consequence of sustained TRPM8 activation by cold and could counteract TRPM8 desensitization enabling a sustained generator potential and a higher density of discharged action potentials. This view is supported by the observation that both camphor and XE991 required TRPM8 activation to induce sensitization to cold, and that XE991 alone had almost no effect on the temperature threshold of activation.

In this respect, our finding of a negative correlation between the magnitude of the cold-sensitizing effect achieved by $\mathrm{M}$-channel inhibitors and the temperature threshold of activation of cold nociceptors (Fig. $8 B, D$ ) may not be explained solely by opposite levels of $\mathrm{K}_{\mathrm{V}} 7$ channel availability. In fact, a similar relationship would be apparent if expression levels of TRPM8 receptors and $\mathrm{K}_{\mathrm{V}} 7$ channels were matched, and $\mathrm{K}_{\mathrm{V}} 7$ block contingent on TRPM8 activation. In this scenario, high TRPM8 activity would always confer high state of $\mathrm{K}_{\mathrm{V}} 7$ block and vice versa. The finding that camphor- and XE991-induced sensitization is entirely absent in TRPM8-deficient mice is in line with the finding that cold sensitization is absent in any non-TRPM8expressing fiber type. The conclusion is clear. Block of $\mathrm{K}_{\mathrm{V}} 7$ can provide considerable amplification of cold transduction, but is too weak to initiate cold transduction without cold-activated TRPM8.

Our study highlights some exquisite differences between cultured sensory cell bodies and cutaneous nerve terminals and shows that the effect of a multiple-target drug like camphor is tightly linked to the ion channel expression profile of the target tissue. This notion is illustrated in particular by the contrasting effects of camphor in low-threshold corneal cold thermoreceptors, where it exerts transient activating and blocking effects due to the exquisitely high expression of TRPM8 (Parra et al., 2010). Last but not least, the recent identification of functional M-channels in keratinocytes and their contribution to ATP release may additionally explain some of the sensitization of camphor to warming of the skin (Mandadi et al., 2009; Reilly et al., 2013).

Taken together, combinations of TRPM8 agonists and locally active M-channel blockers would be a plausible strategy to increase the effectiveness of topical coolants or potentially of cooling- or TRPM8-agonist-mediated analgesia (Liu et al., 2013). Our findings may also shed light on mechanisms of cold allodynia where a pathological state of hyperexcitability can be generated through a block of potassium channels and/or an enhancement of sodium channels (Roza et al., 2006; Eberhardt et al., 2012; Vetter et al., 2012; Deuis et al., 2013).

\section{References}

Alloui A, Zimmermann K, Mamet J, Duprat F, Noël J, Chemin J, Guy N, Blondeau N, Voilley N, Rubat-Coudert C, Borsotto M, Romey G, Heurteaux C, Reeh P, Eschalier A, Lazdunski M (2006) TREK-1, a K+ channel involved in polymodal pain perception. EMBO J 25:2368-2376. CrossRef Medline

Babes A, Zorzon D, Reid G (2004) Two populations of cold-sensitive neurons in rat dorsal root ganglia and their modulation by nerve growth factor. Eur J Neurosci 20:2276-2282. CrossRef Medline

Babes A, Fischer MJ, Reid G, Sauer SK, Zimmermann K, Reeh PW (2010) Electrophysiological and neurochemical techniques to investigate sensory neurons in analgesia research. Methods Mol Biol 617:237-259. CrossRef Medline

Bautista DM, Jordt SE, Nikai T, Tsuruda PR, Read AJ, Poblete J, Yamoah EN, Basbaum AI, Julius D (2006) TRPA1 mediates the inflammatory actions of environmental irritants and proalgesic agents. Cell 124:1269-1282. CrossRef Medline

Bautista DM, Siemens J, Glazer JM, Tsuruda PR, Basbaum AI, Stucky CL, Jordt SE, Julius D (2007) The menthol receptor TRPM8 is the principal detector of environmental cold. Nature 448:204-208. CrossRef Medline

Clapham DE, Miller C (2011) A thermodynamic framework for understanding temperature sensing by transient receptor potential (TRP) channels. Proc Natl Acad Sci U S A 108:19492-19497. CrossRef Medline

Cliff MA, Green BG (1996) Sensitization and desensitization to capsaicin and menthol in the oral cavity: interactions and individual differences. Physiol Behav 59:487-494. CrossRef Medline

Colburn RW, Lubin ML, Stone DJ Jr, Wang Y, Lawrence D, D'Andrea MR, Brandt MR, Liu Y, Flores CM, Qin N (2007) Attenuated cold sensitivity in TRPM8 null mice. Neuron 54:379-386. CrossRef Medline

Daniels RL, Takashima Y, McKemy DD (2009) Activity of the neuronal cold sensor TRPM8 is regulated by phospholipase $C$ via the phospholipid phosphoinositol 4,5-bisphosphate. J Biol Chem 284:1570-1582. CrossRef Medline

Davis JB, Gray J, Gunthorpe MJ, Hatcher JP, Davey PT, Overend P, Harries MH, Latcham J, Clapham C, Atkinson K, Hughes SA, Rance K, Grau E, Harper AJ, Pugh PL, Rogers DC, Bingham S, Randall A, Sheardown SA (2000) Vanilloid receptor-1 is essential for inflammatory thermal hyperalgesia. Nature 405:183-187. CrossRef Medline

Deuis JR, Zimmermann K, Romanovsky AA, Possani LD, Cabot PJ, Lewis RJ, Vetter I (2013) An animal model of oxaliplatin-induced cold allodynia reveals a crucial role for Na1.6 in peripheral pain pathways. Pain 154: 1749-1757. CrossRef Medline

Dhaka A, Murray AN, Mathur J, Earley TJ, Petrus MJ, Patapoutian A (2007) 
TRPM8 is required for cold sensation in mice. Neuron 54:371-378. CrossRef Medline

Dhaka A, Earley TJ, Watson J, Patapoutian A (2008) Visualizing cold spots: TRPM8-expressing sensory neurons and their projections. J Neurosci 28:566-575. CrossRef Medline

Dittert I, Benedikt J, Vyklický L, Zimmermann K, Reeh PW, Vlachová V (2006) Improved superfusion technique for rapid cooling or heating of cultured cells under patch-clamp conditions. J Neurosci Methods 151: 178-185. CrossRef Medline

Dobler T, Springauf A, Tovornik S, Weber M, Schmitt A, Sedlmeier R, Wischmeyer E, Döring F (2007) TRESK two-pore-domain K+ channels constitute a significant component of background potassium currents in murine dorsal root ganglion neurones. J Physiol 585:867-879. CrossRef Medline

Eberhardt MJ, Filipovic MR, Leffler A, de la Roche J, Kistner K, Fischer MJ, Fleming T, Zimmermann K, Ivanovic-Burmazovic I, Nawroth PP, Bierhaus A, Reeh PW, Sauer SK (2012) Methylglyoxal activates nociceptors through transient receptor potential channel A1 (TRPA1). J Biol Chem 287:28291-28306. CrossRef Medline

Egenberger B, Polleichtner G, Wischmeyer E, Döring F (2010) N-linked glycosylation determines cell surface expression of two-pore-domain K+ channel TRESK. Biochem Biophys Res Commun 391:1262-1267. CrossRef Medline

Gamper N, Li Y, Shapiro MS (2005) Structural requirements for differential sensitivity of KCNQ K+ channels to modulation by $\mathrm{Ca} 2+/$ calmodulin. Mol Biol Cell 16:3538-3551. CrossRef Medline

Green BG (1990) Sensory characteristics of camphor. J Invest Dermatol 94: 662-666. CrossRef Medline

Kang D, Kim D (2006) TREK-2 (K2P10.1) and TRESK (K2P18.1) are major background $\mathrm{K}+$ channels in dorsal root ganglion neurons. Am J Physiol Cell Physiol 291:C138-C146. CrossRef Medline

Kang D, Choe C, Kim D (2005) Thermosensitivity of the two-pore domain K+ channels TREK-2 and TRAAK. J Physiol 564:103-116. CrossRef Medline

Karashima Y, Talavera K, Everaerts W, Janssens A, Kwan KY, Vennekens R, Nilius B, Voets T (2009) TRPAl acts as a cold sensor in vitro and in vivo. Proc Natl Acad Sci U S A 106:1273-1278. CrossRef Medline

King CH, Scherer SS (2012) Kv7.5 is the primary Kv7 subunit expressed in C-fibers. J Comp Neurol 520:1940-1950. CrossRef Medline

Linley JE, Rose K, Patil M, Robertson B, Akopian AN, Gamper N (2008) Inhibition of $\mathrm{M}$ current in sensory neurons by exogenous proteases: a signaling pathway mediating inflammatory nociception. J Neurosci 28 : 11240-11249. CrossRef Medline

Linley JE, Pettinger L, Huang D, Gamper N (2012) M channel enhancers and physiological M channel block. J Physiol 590:793-807. CrossRef Medline

Liu B, Fan L, Balakrishna S, Sui A, Morris JB, Jordt SE (2013) TRPM8 is the principal mediator of menthol-induced analgesia of acute and inflammatory pain. Pain. Advance online publication. Retrieved September 16, 2013. doi:10.1016/j.pain.2013.06.043. CrossRef Medline

Love JN, Sammon M, Smereck J (2004) Are one or two dangerous? Camphor exposure in toddlers. J Emerg Med 27:49-54. CrossRef Medline

Macpherson LJ, Hwang SW, Miyamoto T, Dubin AE, Patapoutian A, Story GM (2006) More than cool: promiscuous relationships of menthol and other sensory compounds. Mol Cell Neurosci 32:335-343. CrossRef Medline

Madrid R, de la Peña E, Donovan-Rodriguez T, Belmonte C, Viana F (2009) Variable threshold of trigeminal cold-thermosensitive neurons is determined by a balance between TRPM8 and $\mathrm{K}_{\mathrm{v}} 1$ potassium channels. J Neurosci 29:3120-3131. CrossRef Medline

Mandadi S, Sokabe T, Shibasaki K, Katanosaka K, Mizuno A, Moqrich A, Patapoutian A, Fukumi-Tominaga T, Mizumura K, Tominaga M (2009) TRPV3 in keratinocytes transmits temperature information to sensory neurons via ATP. Pflugers Arch 458:1093-1102. CrossRef Medline

Marsakova L, Touska F, Krusek J, Vlachova V (2012) Pore helix domain is critical to camphor sensitivity of transient receptor potential vanilloid 1 channel. Anesthesiology 116:903-917. CrossRef Medline

McKemy DD, Neuhausser WM, Julius D (2002) Identification of a cold receptor reveals a general role for TRP channels in thermosensation. Nature 416:52-58. CrossRef Medline

Miceli F, Vargas E, Bezanilla F, Taglialatela M (2012) Gating currents from
Kv7 channels carrying neuronal hyperexcitability mutations in the voltage-sensing domain. Biophys J 102:1372-1382. CrossRef Medline

Moqrich A, Hwang SW, Earley TJ, Petrus MJ, Murray AN, Spencer KS, Andahazy M, Story GM, Patapoutian A (2005) Impaired thermosensation in mice lacking TRPV3, a heat and camphor sensor in the skin. Science 307:1468-1472. CrossRef Medline

Noël J, Zimmermann K, Busserolles J, Deval E, Alloui A, Diochot S, Guy N, Borsotto M, Reeh P, Eschalier A, Lazdunski M (2009) The mechanoactivated $\mathrm{K}+$ channels TRAAK and TREK-1 control both warm and cold perception. EMBO J 28:1308-1318. CrossRef Medline

Parra A, Madrid R, Echevarria D, del Olmo S, Morenilla-Palao C, Acosta MC, Gallar J, Dhaka A, Viana F, Belmonte C (2010) Ocular surface wetness is regulated by TRPM8-dependent cold thermoreceptors of the cornea. Nat Med 16:1396-1399. CrossRef Medline

Passmore GM, Reilly JM, Thakur M, Keasberry VN, Marsh SJ, Dickenson AH, Brown DA (2012) Functional significance of M-type potassium channels in nociceptive cutaneous sensory endings. Front Mol Neurosci 5:63. CrossRef Medline

Peier AM, Moqrich A, Hergarden AC, Reeve AJ, Andersson DA, Story GM, Earley TJ, Dragoni I, McIntyre P, Bevan S, Patapoutian A (2002) A TRP channel that senses cold stimuli and menthol. Cell 108:705-715. CrossRef Medline

Reeh PW, Pethö G (2000) Nociceptor excitation by thermal sensitization-a hypothesis. Prog Brain Res 129:39-50. CrossRef Medline

Reid G, Flonta M (2001) Cold transduction by inhibition of a background potassium conductance in rat primary sensory neurones. Neurosci Lett 297:171-174. CrossRef Medline

Reid G, Babes A, Pluteanu F (2002) A cold- and menthol-activated current in rat dorsal root ganglion neurones: properties and role in cold transduction. J Physiol 545:595-614. CrossRef Medline

Reilly JM, Telezhkin V, Passmore GM, Marsh SJ, Brown DA (2013) Kv7/Mtype potassium channels in rat skin keratinocytes. Pflugers Arch 465: 1371-1381. CrossRef Medline

Rohács T, Lopes CM, Michailidis I, Logothetis DE (2005) PI(4,5)P2 regulates the activation and desensitization of TRPM8 channels through the TRP domain. Nat Neurosci 8:626-634. CrossRef Medline

Rose K, Ooi L, Dalle C, Robertson B, Wood IC, Gamper N (2011) Transcriptional repression of the $\mathrm{M}$ channel subunit Kv7.2 in chronic nerve injury. Pain 152:742-754. CrossRef Medline

Roza C, Belmonte C, Viana F (2006) Cold sensitivity in axotomized fibers of experimental neuromas in mice. Pain 120:24-35. CrossRef Medline

Schroeder BC, Kubisch C, Stein V, Jentsch TJ (1998) Moderate loss of function of cyclic-AMP-modulated KCNQ2/KCNQ3 K+ channels causes epilepsy. Nature 396:687-690. CrossRef Medline

Schroeder BC, Hechenberger M, Weinreich F, Kubisch C, Jentsch TJ (2000) KCNQ5, a novel potassium channel broadly expressed in brain, mediates M-type currents. J Biol Chem 275:24089-24095. CrossRef Medline

St. Pierre M, Reeh PW, Zimmermann K (2009) Differential effects of TRPV channel block on polymodal activation of rat cutaneous nociceptors in vitro. Exp Brain Res 196:31-44. CrossRef Medline

Sweetman SC (2004) Martindale: the complete drug reference. London, UK: Pharmaceutical Press.

Teichert RW, Raghuraman S, Memon T, Cox JL, Foulkes T, Rivier JE, Olivera BM (2012) Characterization of two neuronal subclasses through constellation pharmacology. Proc Natl Acad Sci U S A 109:12758-12763. CrossRef Medline

Vetter I, Touska F, Hess A, Hinsbey R, Sattler S, Lampert A, Sergejeva M, Sharov A, Collins LS, Eberhardt M, Engel M, Cabot PJ, Wood JN, Vlachová V, Reeh PW, Lewis RJ, Zimmermann K (2012) Ciguatoxins activate specific cold pain pathways to elicit burning pain from cooling. EMBO J 31:3795-3808. CrossRef Medline

Viana F, de la Peña E, Belmonte C (2002) Specificity of cold thermotransduction is determined by differential ionic channel expression. Nat Neurosci 5:254-260. CrossRef Medline

Voets T, Droogmans G, Wissenbach U, Janssens A, Flockerzi V, Nilius B (2004) The principle of temperature-dependent gating in cold- and heatsensitive TRP channels. Nature 430:748-754. CrossRef Medline

Vogt-Eisele AK, Weber K, Sherkheli MA, Vielhaber G, Panten J, Gisselmann G, Hatt H (2007) Monoterpenoid agonists of TRPV3. Br J Pharmacol 151:530-540. CrossRef Medline

Wang HS, Pan Z, Shi W, Brown BS, Wymore RS, Cohen IS, Dixon JE, McKinnon D (1998) KCNQ2 and KCNQ3 potassium channel subunits: mo- 
lecular correlates of the M-channel. Science 282:1890-1893. CrossRef Medline

Xu H, Blair NT, Clapham DE (2005) Camphor activates and strongly desensitizes the transient receptor potential vanilloid subtype 1 channel in a vanilloid-independent mechanism. J Neurosci 25:8924-8937. CrossRef Medline

Xu H, Delling M, Jun JC, Clapham DE (2006) Oregano, thyme and clovederived flavors and skin sensitizers activate specific TRP channels. Nat Neurosci 9:628-635. CrossRef Medline

Yudin Y, Lukacs V, Cao C, Rohacs T (2011) Decrease in phosphatidylinositol 4,5-bisphosphate levels mediates desensitization of the cold sensor TRPM8 channels. J Physiol 589:6007-6027. CrossRef Medline
Zimmermann K, Leffler A, Babes A, Cendan CM, Carr RW, Kobayashi J, Nau C, Wood JN, Reeh PW (2007) Sensory neuron sodium channel Nav1.8 is essential for pain at low temperatures. Nature 447:855-858. CrossRef Medline

Zimmermann K, Hein A, Hager U, Kaczmarek JS, Turnquist BP, Clapham DE, Reeh PW (2009) Phenotyping sensory nerve endings in vitro in the mouse. Nat Protoc 4:174-196. CrossRef Medline

Zimmermann K, Lennerz JK, Hein A, Link AS, Kaczmarek JS, Delling M, Uysal S, Pfeifer JD, Riccio A, Clapham DE (2011) Transient receptor potential cation channel, subfamily $\mathrm{C}$, member 5 (TRPC5) is a coldtransducer in the peripheral nervous system. Proc Natl Acad Sci U S A 108:18114-18119. CrossRef Medline 